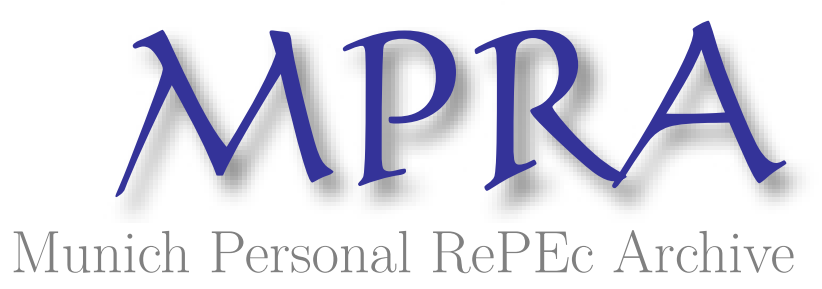

Rules of Origin Liberalization with Multi-Product Firms: Theory and Evidence from Bangladeshi Apparel Exporters

Sytsma, Tobias

10 September 2019

Online at https://mpra.ub.uni-muenchen.de/95956/

MPRA Paper No. 95956, posted 13 Sep 2019 09:56 UTC 


\title{
Rules of Origin Liberalization with Multi-Product Firms: Theory and Evidence from Bangladeshi Apparel Exporters
}

\author{
Tobias Sytsma \\ University of Oregon
}

September 10, 2019

\begin{abstract}
I study how rules of origin in potential export destinations influence firm- and industry-level export behavior in least-developed countries (LDCs). Rules of origin restrict LDCs from taking advantage of preferential tariff rates in export markets, and this undermines market access for LDCs and reduces the efficacy of exportoriented industrialization. I develop a model of multi-product firms in which rules of origin influence the product scope and export revenue of final goods producers through their effect on input sourcing decisions. I test the model's predictions using the 2011 revisions to the EU's rules of origin for apparel products from LDCs. To control for the potential endogeneity of the policy change I use a triple-difference approach, exploiting variation in the input-cost differentials across apparel products and export destination, before and after the EU policy change. Liberalizing rules of origin results in revenue gains, expansion of product scope, and firm entry into the export market. Within firms, incumbents upgrade product quality. Across firms, market share is reallocated toward more productive incumbents.
\end{abstract}

Keywords: Rules of origin, Non-tariff barriers, Economic development, Exports-oriented industries, Ready-made garments

JEL Codes: F13, F61, L25, O24

Acknowledgments: I thank Bruce Blonigen, Anca Cristea, and Wesley W. Wilson for their comments. I also thank participants at the UO International Trade Workshop, and UO Microeconomics Workshop, Oregon State School of Public Policy, Northwest Development Workshop 2019, and the Midwest International Trade Conference 2019 for comments. All errors are my own. 


\section{Introduction}

In an effort to integrate least-developed countries (LDCs) into the global economy, industrialized countries have been offering preferential treatment to imports from LDCs for several decades. For example, the EU offers reduced tariff rates on the majority of imported goods from LDCs. The United States, Canada, and other industrialized countries offer similar programs to LDCs. However, existing research indicates that only a fraction of imports from LDCs actually receive the preferential treatment they are offered by these programs (Hakobyan, 2015; Carrere and de Melo, 2004; Wijayasiri, 2007; Brenton, 2006). This has led the World Trade Organization (WTO) to focus on non-tariff barriers faced by LDCs during the Doha Round of global trade negotiations. ${ }^{1}$ Chief among the concerns raised by LDCs in the Doha Round were the restrictive nature of rules of origin in potential export markets (Barber, 2004).

Rules of origin are the criteria used to establish the nationality of a final good, and used to determine whether or not an imported product qualifies for preferential treatment. Typically, rules of origin require a "sufficient transformation" of imported intermediate inputs or a specific amount of local content in imported products. Satisfying rules of origin that require a large fraction of local content, or a capital-intensive transformation of inputs is difficult for exporters in LDCs, where value added to final goods typically only comes from labor. This keeps LDCs from taking advantage of preferential trade agreements. As result, tariffs applied in industrialized countries to imported goods from LDCs tend to be higher than the preferential rates that are offered. In this sense, rules of origin can undermine market access for LDCs and reduce the efficacy of export-oriented industrialization.

In this paper, I study how rules of origin in potential export destinations influence firm- and industry-level export behavior in LDCs. There is a growing literature on trade responses to rules of origin. The existing literature provides evidence that country-

\footnotetext{
${ }^{1}$ https://www.wto.org/english/tratop_e/devel_e/dev_special_differential_provisions_e.htm
} 
level trade flows respond to changes in rules of origin policies (Curran and Nadvi, 2014; Bombarda and Gamberoni, 2009; Conconi et al, 2018) and provides evidence on how firms endogenously sort across export markets based on differences in rules of origin in the cross-section (Demidova et al, 2012; Cherkashin et al, 2015; Kee and Krishna, 2008). However, the response of firms to liberalization of rules of origin associated with existing preferential trade agreements is scarce. ${ }^{2}$ The recent attention to rules of origin revisions under NAFTA highlights the need for an analysis of how rules of origin influence firmlevel export performance. ${ }^{3}$ Furthermore, understanding the firm-level responses to rules of origin revisions is necessary for developing effective trade policy, especially in LDCs where export-industries are important drivers of economic development.

I develop a model of multi-product firms in which rules of origin in potential export destinations influence the product scope and export revenue of final goods exporters through their effect on input sourcing decisions. While Demidova et al. (2012) and Bombarda and Gamberni (2009) show how rules of origin can be incorporated into heterogeneous firm models, I show how incorporating multi-product firms produces new margins over which exporters respond to rules of origin. Specifically, I show that liberalizing rules of origin in a multi-product firm setting not only affects input sourcing decisions and trade preference utilization rates, but also product output mix.

I test the model's predictions using the 2011 revisions to the EU's rules of origin for apparel products from LDCs. The revision allowed apparel producers in LDCs to use more imported content in their exported products, which alleviated the capacity constraints in the production of textiles in LDCs. To control for the potential endogeneity of the policy change, I use a triple-difference approach, exploiting variation in the inputcost differentials across apparel products and export destinations, before and after the EU policy change.

\footnotetext{
${ }^{2}$ One exception to this is Cadot et al (2014), who analyze how firm-level export revenue responds to rules of origin changes in Colombia. However, the authors note they are unable to disentangle the effects of the rules of origin liberalization from tariff rate changes that occurred at the same time.

${ }^{3}$ See: https://piie.com/newsroom/short-videos/toughening-naftas-rules-origin-could-backfire
} 
Using firm-level transaction data for Bangladeshi apparel exporters I find evidence that the revision of the rules of origin resulted in export revenue gains, expansion of exported product scope, and entry into the export market. Additionally, I find evidence that incumbent firms upgraded product quality and reduced quality-adjusted prices. To my knowledge, this is the first study to link rules of origin with exported product quality. The existing literature has focused almost exclusively on product quality responses to liberalization of input and output tariffs (Bas and Strass-Khan, 2014; Amiti and Khandelwal, 2013; Fan et al., 2105; Bas, 2012). ${ }^{4}$ The expansion of product-scope and upgrading the quality of exiting product lines are important facets of export-oriented growth policies, thus the results in this paper underscore the policy concerns of LDCs regarding restrictive rules of origin. Finally, I find that within the apparel export industry market share was reallocated toward more productive incumbents after the policy change.

The remainder of this paper is organized as follows. In Section 2, I discuss the context in which this study takes place. In Section 3, I present the theoretical model and discuss the models predictions. In Sections 4 and 5, I discuss the empirical framework and present the empirical results. In Section 6, I analyze the robustness of the main results. In Sections 7 and 8 I examine additional within-firm and industry-level responses, respectively. Finally, Section 6 concludes.

\section{Institutional Context}

This section provides a brief overview of the institutional context of the apparel industry in Bangladesh, and market access to EU countries for Bangladeshi apparel exporters.

\footnotetext{
${ }^{4}$ One exception is Khandelwal, Schott, and Wei (2013), who study the effects of the removal of export quotas on Chinese apparel firms.
} 


\subsection{The EU's Everything But Arms Agreement}

The EU's Generalized System of Preferences (GSP) is a unilateral agreement that grants preferential tariff treatment for imports of goods from many developing countries. Within the GSP, the "Everything But Arms" (EBA) arrangement allows for duty-free and quota-free trade in all goods, except arms and ammunition, between EU countries and 48 LDCs. $^{5}$ The EBA went into effect in 2001, with the stated goal of helping LDCs integrate further into the global economy. Under the EBA, apparel and clothing imports into the EU would be granted preferential treatment if they were made under a "double-transformation" process. Double-transformation refers to a production process where imported inputs are transformed at least two times before being exported as final goods. For example, in order to export a t-shirt to the EU and qualify for the preferential treatment under the EBA, the t-shirt must be made from fabric that was also produced within the exporting country.

While the rule was designed to encourage backward-linkages in developing economies, it was criticized for being too difficult for many producers to satisfy (Barber et al., 2004). Small concessions were made in the EBA at the time it was ratified; for example, allowing garments made from textiles imported from other LDCs to qualify for the EBA arrangement (Sekkel, 2009). However, even with these concessions it remained difficult for apparel producers to satisfy the rules of origin. Apparel products made from textiles imported from major textiles producers like China, Hong Kong, India, and Pakistan would not qualify for the EBA, as these countries were not LDCs as determined by the United Nations. According to COMTRADE data, only $1 \%$ of woven textile imports into Bangladesh came from other LDCs, and the vast majority (roughly 70\%) of imports came from China and Hong Kong. Most Favored Nation (MFN) tariffs of between $12 \%$ and $15 \%$ tariff was applied to apparel goods that were not able to satisfy these

\footnotetext{
${ }^{5}$ The least developed country label is given to developing countries by the United Nations. It is based on levels of poverty, resource weakness, and economic instability. The number of LDCs have change over time, but at the time of the EBA revision there were 48 LCDs. Currently, in 2018, there are 47.
} 
rules of origin. Recognizing the reliance of the ready-made-garment sector on imported intermediate inputs, Bangladesh has a duty-free policy of their own for imports of textiles used in exported apparel products (Kabir et al., 2019). Thus, for export-oriented firms, a major cost associated with imported textiles came from the inability of exporters to utilize preferential trade agreements like the EBA.

On November 18th, 2010, the EU announced there would be a revision of the rules of origin associated with the EBA for a number of goods. Then, on January 1st, 2011, the new rules of origin were put into effect. While discussions of a revision to the rules of origin had been on-going for several years, the first announcement of the rule changes came in November of 2010. One of the largest changes came in the form of a relaxation of the double-transformation policy for apparel, which was changed to a single-transformation policy. The single-transformation policy allows for apparel made from imported textiles to qualify for the preferential treatment under the EBA regardless of the source.

The garment industry accounts for over three quarters of Bangladeshi export value (Ahsan and Iqbal, 2017), and roughly 13 percent of GDP (Heath, 2018). Roughly 80 percent of exports from Bangladesh are apparel (HS codes 61 and 62), approximately 51 percent of which goes to EU countries. Naturally, the change to a single-transformation policy had the potential to greatly influence Bangladeshi exports, and the economy as a whole, as the apparel manufacturing industry employs roughly 40 percent of the country's labor force (Curran and Nadvi, 2014). Anecdotal evidence of the influence of the policy change can be seen in Figure 1. Using data from the World Bank Enterprise Survey, the figure shows survey responses of Bangladeshi apparel firms to a question of "To what degree is customs and trade regulation an obstacle to the current operations of this establishment?" when asked in 2011 and 2013. Figure 1 suggests that apparel exporters found customs and trade regulations less burdensome after the rules of origin associated with exports to a major trade partner (the EU) were relaxed. 
Importance of Customs and Trade Regulations as Trade Obstacle for Apparel Exporters

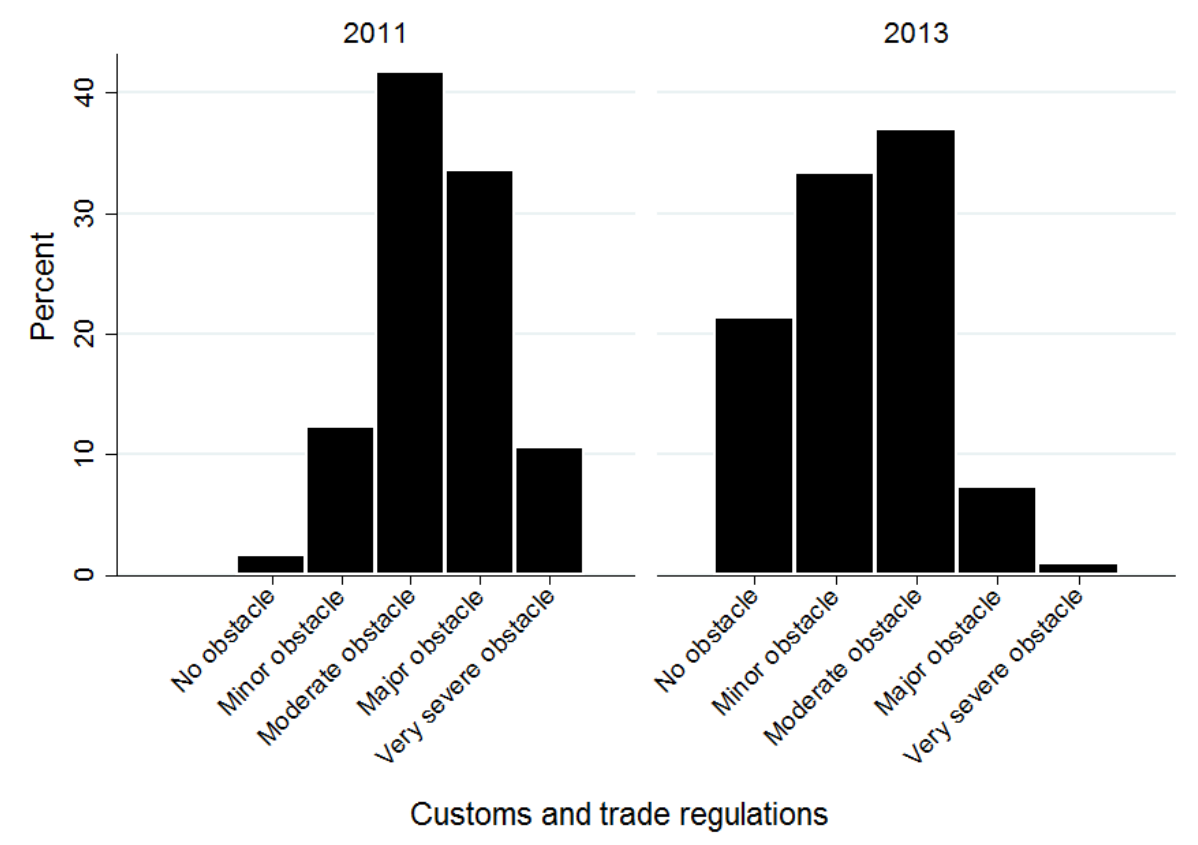

Figure 1: This figure displays the responses from the World Bank Enterprise Survey for Bangladeshi apparel firms. Data for this figure was collected from the 2011 and 2013 round of the survey. The responses are for exporting apparel firms only. Respondents were asked how much an obstacle customs and trade regulations were. No data for apparel firms was available before 2011. The survey responses were collected between May and June 2011, roughly six months after the policy change went into affect. 
More direct evidence of the effect of the revision to the double-transformation policy can be seen in Figure 2. This figure displays the utilization rate of the EBA by Bangladeshi apparel exporters. The utilization rate is calculated as the fraction of EU apparel imports from Bangladesh processed under the EBA, relative to the total EU apparel imports from Bangladesh. The data from the figure comes from EuroStat's Imports by Tariff Regime database. The top panel of the figure displays the total change in utilization rates. In 2011, the rate increases roughly 15 percentage points. The bottom panel of the figure breaks down the utilization rates by product type. As is evident, woven apparel products responded dramatically to the policy change, while knitted products did not respond. Relative to the change in the utilization rate for knitted products, the utilization rate for woven products increased by roughly 50 percentage points. The restrictive nature of the double-transformation policy for woven products is discussed further in the next section.

\subsection{The Apparel Export Industry in Bangladesh}

Due to its large labor force, Bangladesh has had a comparative advantage in apparel assembly (a labor-intensive process) for several decades. Unlike other major garment producing countries, apparel production is mainly locally financed. In 2005, roughly $97 \%$ of apparel firms only sourced capital locally (Bakht et al, 2006). By 2016, this number had only fallen to 91\% (Lopez-Acevedo and Robertson, 2016). While assembling apparel is a labor-intensive process, the full production process involves several capital-intensive stages. As discussed in Curran and Nadvi (2014), apparel manufacturing takes place in three broad stages: (1) spinning of yarn from natural or man-made fibers, (2) the production of fabric or textiles, and (3) the production of a final apparel good. In the case of Bangladesh (and many other LDCs), much of this final apparel product is exported. While the third stage is a labor-intensive process, the first two are more capital-intensive. 
Change in EBA utilization rate for apparel products
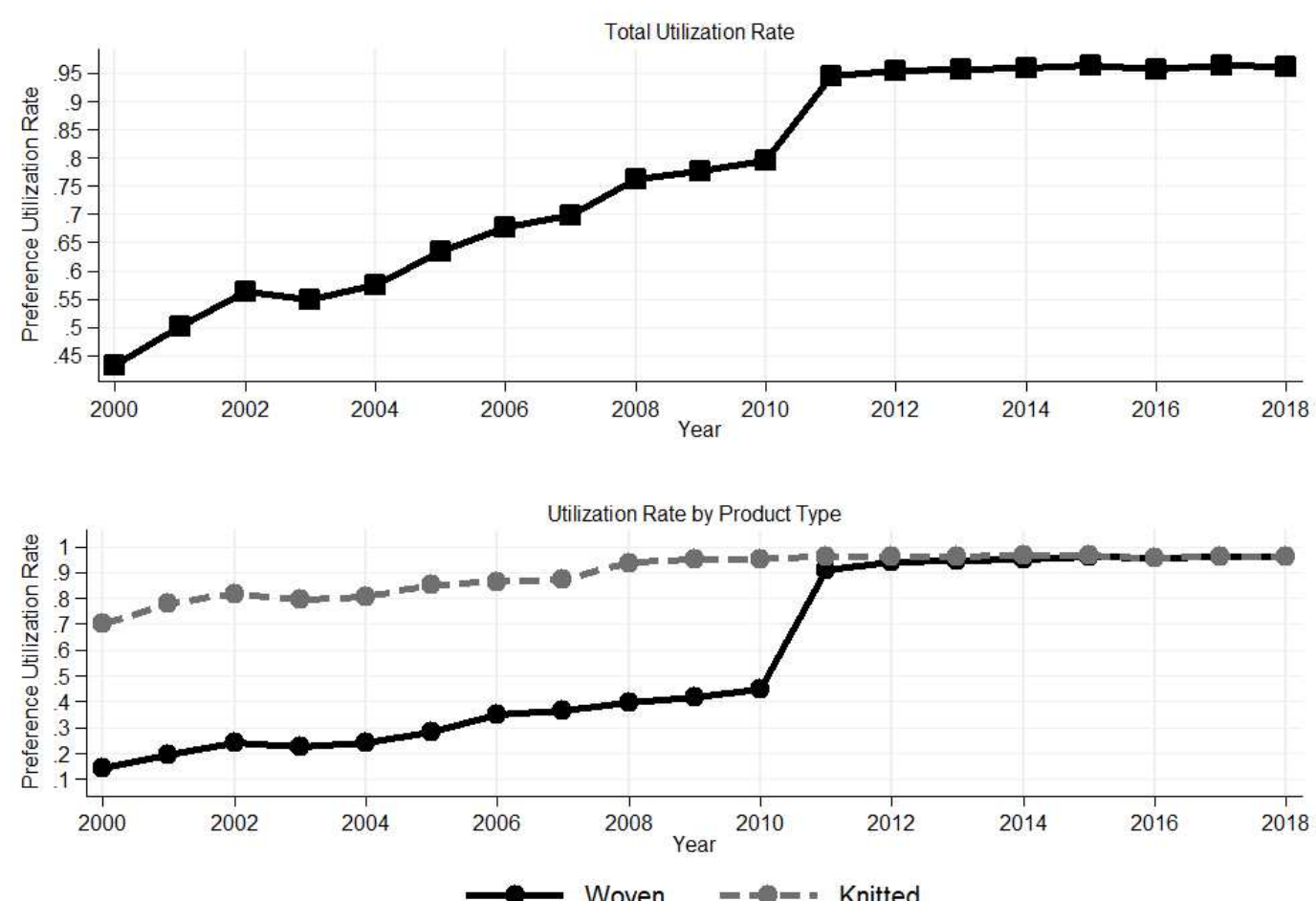

Figure 2: This figure displays utilization rate of the EBA for Bangladeshi apparel products. The data comes from EuroStat. The utilization rate is calculated as the value of imports into the EU that were processed under the EBA, relative to the total value of imports into the EU regardless of how the imports were processed. 
Table 1: Textile Sourcing in Bangladesh

\begin{tabular}{l|c|c} 
Study & \% Knit Textiles Locally Sourced & \% Woven Textiles Locally Sourced \\
\hline Fredric and Staritz (2012) & $60-70 \%$ & $12-15 \%$ \\
\hline Masum (2016) & $90 \%$ & $40 \%$ \\
\hline Hayashi (2007) & $80 \%$ & $<30 \%$ \\
\hline
\end{tabular}

The general process outlined above is similar for all apparel, however there is heterogeneity in the amount of capital needed to produce different fabrics. Broadly speaking, this difference can be seen in the production of woven versus knitted fabric. Production of woven fabric requires weaving multiple threads over and under each other in a criss-cross pattern, and is done in large plants. As noted in Frederic and Staritz's (2012) study of the Bangladeshi textile and apparel industry, producing woven fabrics is an energy-intensive process, and while labor-intensive hand-looms can produce woven fabric they are typically too inefficient to use at a large scale. Other stages of woven textile production, like dying, are also capital-intensive. Knitted fabric, on the other hand, is much less capital-intensive to produce. In fact, many knitted apparel products can be directly made from yarn, "bypassing" the second stage of production outlined above. $^{6}$ As a result, Bangladeshi knitted garments are much less reliant on imported intermediate inputs than woven garments.

Several studies provide estimates of the ability of Bangladesh's textile industry to supply the apparel industry. Table 1 displays estimates from three studies on the percent of textiles sourced locally in Bangladesh for woven and knitted apparel products. In all cases, the percent of locally sourced textiles used in woven apparel production is substantially lower than locally sourced knitted textiles.

Given these differences in the production process of woven versus knitted apparel, the change in the rules of origin from a double-transformation to single-transformation was likely to affect woven apparel exports more than knitted apparel exports. Evidence of this discrepancy can be seen in the change in EBA utilization rates in the bottom

\footnotetext{
${ }^{6}$ Producing knitted garments in this way would still qualify as a double-transformation, because the garment would be entirely composed of textiles made within Bangladesh.
} 
panel of Figure 2. For exporters of woven apparel, the new rules grant woven clothing preferential treatment even if made completely from imported fabric. This difference helps inform the empirical framework used in this paper.

\section{A model with heterogeneous multi-product firms and rules of origin}

In this section I outline a model of trade that extends the multi-product firm model in Bernard, Redding, and Schott (2011) (BRS hereafter), and the demand-shock model in Demidova et al (2012). The multi-product firm framework is appropriate in this situation as Bangladeshi apparel firms export an average of five products per destination (as shown in Table 4). The focus of the model is on final good producers, and abstracts away from the intermediate good sector. This is done due to data limitations (I do not have data that would allow me to analyze the intermediate sector), and due to the relative size of the final goods apparel sector compared to the textile sectors in LDCs.

In the model, firms decide whether to enter an export market, which products to supply, and whether to export while invoking the rules of origin or export without invoking the rules of origin. Invoking the rules of origin is costly, but doing so grants a firm access to preferential tariff rates under a preferential trade agreement. Products are imperfect substitutes, and each firm can produce a differentiated variety of each product. Production requires labor and an intermediate input, and competition is monopolistically competitive.

\subsection{Modeling decisions}

As discussed in other studies of the Bangladeshi apparel export sector, there is a considerable amount of idiosyncratic variation in exports across destinations. For example, using data from 2004, Demidova et al (2012) note the lack of apparent market "hiearchary". They show that Bangladeshi apparel firms appear to export products to highly compet- 


\begin{tabular}{l|c} 
Fixed Effects & $R^{2}$ \\
\hline Dest-HS8 & .106 \\
Dest-HS8+Firm & .298 \\
Dest-HS8 + Firm-HS8 & .611
\end{tabular}

Table 2: $R^{2}$ from regressions of log firm sales on different sets of fixed effects.

itive markets without exporting the same products to less competitive ones.

The lack of market hierarchy is apparent in Bangladeshi apparel firm export decisions is explained by idiosyncratic product demand shocks across import markets. I document this using an analysis of explained variation in the sales of exported apparel products in 2010, the year prior to the rules of origin revision in the EU. Table 2 displays the $R^{2}$ statistic when regressing the log of export revenue-measured at the firm, destination, and HS8 product level-on a variety of fixed effects.

The Destination-product fixed effects, which control for any common trade barriers across firms in Bangladesh exporting a given product, explain roughly 11 percent of the variation in log export sales. The addition of firm fixed effects, which control for firm ability, explain roughly $33 \%$ of the remaining $89.4 \%$ of the variation in log export sales after the inclusion of destination-product fixed effects. Firm-product fixed effects, which control for firm ability, and the average product attributes across the range of products a firm sells, account for roughly $44 \%$ of the remaining variation. This leaves roughly $20 \%$ of the variation unexplained. I introduce destination-product specific demand shocks, which allows me to incorporate this variation into the model.

\subsection{Demand}

Following BRS, there is a representative consumer in each country $j \in J$ who has CES utility over a continuum of products. The continuum of products is normalized to the interval $[0,1]$. 


$$
U_{j}=\left[\int_{0}^{1} C_{j k}^{\eta} d k\right]^{1 / \eta}
$$

Here, $k$ indexes products, and $\eta$ is the elasticity of substitution across products. $C_{j k}$ is a consumption index. The consumption index also takes the CES form, and depends on the varieties consumed:

$$
C_{j k}=\left[\sum_{i=1}^{J} \int_{\omega \in \Omega_{i j k}}\left(\lambda_{i j k}(\omega) c_{i j k}(\omega)\right)^{\rho} d \omega\right]^{\frac{1}{\rho}}
$$

where $\omega$ indexes varieties of product $k, \Omega_{i j k}$ is the set of all products available in country $j$ from country $i$, and $\lambda_{i j k}(\omega)$ represents a "product attribute", as in BRS. The product attribute term encompasses product quality (which may be the same in all $j$ ), as well as idiosyncratic taste variation that differs across $j$ 's. The fact that the product attribute term is country specific means that product attributes enter the utility of consumers in different countries differently. In this sense, the $\lambda_{i j k}(\omega)$ term is similar to the demand-shock term in Demidova et al (2012), but allows for variation across products as well.

Defining $\sigma \equiv \frac{1}{1-\rho}>1$ as the elasticity of substitution across varieties within products, the corresponding price index is:

$$
P_{j k}=\left[\sum_{i} \int_{\omega \in \Omega_{i j k}}\left(\frac{p_{i j k}(\omega)}{\lambda_{i j k}(\omega)}\right)^{1-\sigma} d \omega\right]^{1 /(1-\sigma)}
$$

\subsection{Firms}

There is an unbounded measure of potential firms, each of which can supply a horizontally differentiated variety of each of the continuum of products. Firms are differentiated by their ability, $\phi$. To enter the domestic market, firms must pay a fixed entry cost, $f_{e}$. After paying the fixed entry cost firms observe their ability, which is drawn from a continuous distribution $g(\phi)$, with $\operatorname{CDF} G(\phi)$. Because I work with data containing in- 
formation only on exports, I assume that all firms who export have already paid the fixed entry cost and observed their productivity. Ultimately, this assumption does not affect the model going forward, however, it abstracts away entry into the domestic market. ${ }^{7}$

Firms are also differentiated by their product attributes, $\lambda_{j k}$. Product attributes, which are drawn from a known distribution $z(\lambda)$ and are independently and identically distributed across the continuum of products. ${ }^{8}$ Product attributes are drawn separately for each destination and product pair. This captures the idiosyncrasies in apparel product demand documented in Demidova et al (2012), Kee and Krishan (2008), and documented in section 3.1.

\subsection{Production}

To see how restrictive rules of origin influence the production of final goods, consider the simple production function for a firm with productivity $\phi$ :

$$
q_{k}=f\left(\phi, L, X_{k}\right)
$$

Here, production of product $k$ requires only labor $(\mathrm{L})$ and a single intermediate good $\left(X_{k}\right)$. This single intermediate good is produced in a perfectly competitive global market, where producers of the intermediate good may also differ in terms of productivity. Following Eaton and Kortum (2002), producers of the final good search for the lowest price of this intermediate good, paying $p_{x, k}=\min _{m \in J}\left(p_{x, k}^{m}\right)$, where $m$ denotes global producers of the intermediate good, with potentially $m=i$. In this sense, $p_{x, k}$ can be thought of as the lowest global price for input $\mathrm{X}$ inclusive of any potential trade costs associated with importing the good from other countries. Rules of origin that place

\footnotetext{
${ }^{7}$ It should be noted that the "domestic market" in the case of the Bangladeshi apparel industry mainly consists of factory seconds. Given that the vast majority of apparel produced by Bangladeshi apparel firms is exported and the lack of domestic retail stores there are few firms that produce exclusively for the domestic market (Lopez-Acevedo and Robertson, 2016).

${ }^{8}$ These assumptions simplify the calculations going forward by letting firms profit-maximize over each product separately. Ultimately, they do not change the models predictions on how firms respond to rules of origin liberalization.
} 
limits on where inputs can be sourced will restrict the set of potential prices over which firms can search for a minimum. The restriction on the set of prices over which firms can search will result in the lowest input price being greater than or equal to the unrestricted price.

To further solidify this concept, I assume $f\left(\phi, L, X_{k}\right)$ is Cobb-Douglas. This results in a marginal cost for a firm with productivity $\phi$ producing good $k$ of:

$$
c_{k}\left(\phi, w, P_{x, k}\right)=\frac{\Gamma w^{\alpha} p_{x, k}^{\beta}}{\phi}
$$

where $w$ is the wage, and $\Gamma$ is a constant ${ }^{9}$, and $\alpha$ and $\beta$ are output elasticities. Wages are assumed to be constant across products, and are normalized to one going forward.

Exporting to country $j$ involves paying iceberg trade costs, $\tau_{j}>1$. Trade costs include transport costs, tariffs, and other trade barriers which vary by country. If a firm invokes the rules of origin for country $j$, its products are exposed to lower tariff rates. I define $\tau_{j}^{P T A}$ and $\tau_{j}^{M F N}$ as the trade costs associated with the preferential trade agreement (PTA) associated with invoking the rules of origin, and the non-rules of origin trade costs (MFN) associated with exports that do not meet the rules of origin standards and to which MFN tariffs are applied. Because firms invoking the rules of origin face lower tariffs, $\tau_{j}^{P T A}<\tau_{j}^{M F N}$. To invoke the rules of origin, firms can only source the intermediate input from specific countries. This restricts the set of global prices over which firms can search for the lowest $p_{x, k}$, resulting in firms paying $\bar{p}_{x, k} \geq p_{x, k}$ for the input. ${ }^{10}$ Normalizing wages to one, the total cost functions for firms that invoke rules of origin (PTA), and those that do not (MFN) are shown below:

$$
T C_{j k}^{P T A}(\phi, \lambda)=\left(F_{j}+f_{j k}+d_{j}+\frac{\tau_{j}^{P T A} \Gamma q_{j k}(\phi, \lambda) \bar{p}_{x, k}^{\beta}}{\phi \lambda_{j k}}\right)
$$

${ }^{10}$ Demidova et al (2012) estimate that the cost of using woven textiles made in Bangladesh for the production of apparel is roughly $15 \%$ higher than importing it from other countries.
} 


$$
T C_{j k}^{M F N}(\phi, \lambda)=\left(F_{j}+f_{j k}+\frac{\tau_{j}^{M F N} \Gamma q_{j k}(\phi, \lambda) p_{x, k}^{\beta}}{\phi \lambda_{j k}}\right)
$$

Along with the marginal costs of producing and exporting discussed above the total cost of exporting a product to country $j$ also depends on several fixed costs. First, regardless of how a firm decides to export its product it must pay a market-entry fixed cost $F_{j}$. This accounts for factors like market research, or any cost associated with learning about destination market $j$. For any product the firm decides to export, there are additional fixed costs associated with advertising, setting up distributors for the product, and so on. These fixed costs are captured by the $f_{j k}$ term. This term is product specific because some products may require different types of advertising, or have different general product standards required in country $j$. Finally, if a firm decides to export the product while invoking the rules of origin, it must document that the rules of origin were satisfied. Previous research has shown that this documentation cost is high for many firms in LDCs (Brenton, 2003). The term $d_{j}$ captures this fixed cost. ${ }^{11}$

The firm's profit maximization problem results in choosing a price for each product separately, and under monopolistic competition this results in a price that is a constant mark-up over the marginal cost. The price set for product $k$, with attributes $\lambda_{j k}$, by a firm with productivity $\phi$ choosing to either meet, not meet, the rules of origin are given by:

$$
\begin{aligned}
p_{j k}^{P T A}(\phi, \lambda) & =\frac{\tau_{j}^{P T A} \bar{p}_{x, k}^{\beta}}{\chi \phi \lambda_{j k}} \\
p_{j k}^{M F N}(\phi, \lambda) & =\frac{\tau_{j}^{M F N} p_{x, k}^{\beta}}{\chi \phi \lambda_{j k}}
\end{aligned}
$$

\footnotetext{
${ }^{11}$ This fixed cost can be thought of as gaining legal insight into documenting the rules of origin for country $j$. It is not product specific, however, allowing it to vary by product would not change the predictions of the model.
} 
where $\chi=\frac{\rho}{\Gamma}$ and is a constant. As can be seen in the pricing rules above, the higher a firms productivity $(\phi)$ the lower the price it will charge for good $k$. Similarly, the more attractive a firms variety of product $k$ is in country $j\left(\lambda_{j k}\right)$ the lower the optimal price. Given these pricing rules, export revenue and profits for firms invoking the rules of origin (PTA) and those not meeting the rules of origin (MFN) are as follows:

$$
\begin{gathered}
r_{j k}^{P T A}(\phi, \lambda)=\left(\tau_{j}^{P T A} \bar{p}_{x, k}^{\beta}\right)^{(1-\sigma)} \frac{1}{\sigma} E_{j k}\left(P_{j k} \chi\right)^{\sigma-1} \phi^{\sigma-1} \lambda_{j k}^{\sigma-1} \\
\pi_{j k}^{P T A}(\phi, \lambda)=r_{j k}^{P T A}(\phi, \lambda)-f_{j k}-d_{j} \\
r_{j k}^{M F N}(\phi, \lambda)=\left(\tau_{j}^{M F N} p_{x, k}^{\beta}\right)^{(1-\sigma)} \frac{1}{\sigma} E_{j k}\left(P_{j k} \chi\right)^{\sigma-1} \phi^{\sigma-1} \lambda_{j k}^{\sigma-1} \\
\pi_{j k}^{M F N}(\phi, \lambda)=r_{j k}^{M F N}(\phi, \lambda)-f_{j k}
\end{gathered}
$$

where, $E_{j k}$ is the total expenditure in country $j$ on product $k$. Given the competitive nature of the global apparel industry, I assume a firm is unable to influence the price index for any product. ${ }^{12}$ In order for any firm to find it profitable to invoke the rules of origin the condition $\frac{\tau_{j}^{M F N}}{\tau_{j}^{P T A}}>\left(\frac{\bar{p}_{x, k}}{p_{x, k}}\right)^{\beta}$ must hold. Otherwise, $r_{j k}^{P T A}<r_{j k}^{M F N}$ for any level of firm ability. ${ }^{13}$ The ratio between the price firms pay for the intermediate input when invoking the rules of origin relative the global minimum price captures the restrictive nature of rules of origin on firm's sourcing decisions.

\subsection{Product-level profitability}

Given this set up, only products with desirable enough attributes will allow a firm of ability $\phi$ to generate enough revenue to cover the product fixed cost of exporting to

\footnotetext{
${ }^{12}$ Although the price index is treated as exogenous in this paper, the price index can be endogenenized. Essentially, the endogeneity of the price index results in predictions similar to those found in Bombarda and Gamberni (2009). When the rules of origin are liberalized, high productivity incumbents lower their prices and the overall price index in $j$ falls. This reduces the profitability of low productivity incumbents and forces them out of the market. Empirically, I do not find support for this prediction in the data.

${ }^{13}$ Note that this condition is consistent with the empirical work in Demidova et al. (2012), where it is estimated that sourcing woven textiles locally costs $15 \%$ more than importing them.
} 
country $j$. Furthermore, only products with the most desirable attributes will allow firms to invoke the rules of origin because the fixed costs and marginal costs are higher. Therefore, within a firm, there is endogenous sorting of exported products between those exported using the rules of origin and those that are not. I define two zero-profit product attribute cutoffs, $\lambda_{j k}^{M F N}(\phi)$ and $\lambda_{j k}^{P T A}(\phi)$ to capture the endogenous thresholds above which a product will be exported without using the rules of origin, and when they will be exported using the rules of origin, respectively.

The zero-profit product attribute cutoff $\lambda_{j k}^{M F N}(\phi)$ is the lowest level of product attributes that are sufficient to generate enough profits to export a product without invoking the rules of origin. That is, it is the minimum level of product attributes for a firm with ability $\phi$ that allow the firm to export the product profitably to country $j$. The second zero-profit product attribute cutoff $\lambda_{j k}^{P T A}(\phi)$ is the lowest level of product attributes for a firm with productivity $\phi$ that allows the firm to profitably export the product to country $j$ while invoking the rules of origin. The zero-profit product attribute cutoffs are defined as:

$$
\begin{gathered}
r_{j k}^{M F N}\left(\phi, \lambda_{j k}^{M F N}(\phi)\right)=\sigma f_{j k} \\
r_{j k}^{P T A}\left(\phi, \lambda_{j k}^{P T A}(\phi)\right)=\sigma\left(f_{j k}+d_{j}\right)
\end{gathered}
$$

Equations (12) and (13) highlight how the fixed costs of invoking the rules of origin affect the range of products a firm of ability $\phi$ is able to export to country $j$. The higher the documentation costs, the higher the zero-profit cutoff for product attributes necessary for exporting under the preferential trade agreement. The equations also show how both zero-profit cutoffs for product attributes increase as the elasticity of substitution increases. That is, as the varieties of product $k$ become more substitutable competition increases and firms must export products with better attributes in order to 
cover the fixed exporting costs.

Products with $\lambda_{j k}<\lambda_{j k}^{M F N}(\phi)$ will not be able to generate enough revenue to cover the fixed cost of exporting a product to country $j$, even without invoking the rules of origin. Products with attributes $\lambda_{j k} \in\left[\lambda_{j k}^{M F N}(\phi), \lambda_{j k}^{P T A}(\phi)\right)$ will be profitable to export to country $j$ without invoking rules of origin, but not profitable enough to export to $j$ under the preferential trade agreement. Finally, products with $\lambda_{j k}>\lambda_{j k}^{P T A}(\phi)$ will be profitable to export to country $j$ while invoking the rules of origin. Thus, within a firm, there is sorting across products based on how attractive the product is in country $j$. This is shown graphically in Figure 3 .

Using the zero-profit cutoffs above, the relative revenue for a firm of ability $\phi$, between using the rules of origin and not using the rules of origin can be expressed as:

$$
\lambda^{P T A}(\phi)=\lambda^{M F N}(\phi)\left(\frac{f_{j k}+d j}{f_{j k}}\right)^{\frac{1}{\sigma-1}}\left(\frac{\tau_{j}^{P T A} \bar{p}_{x, k}^{\beta}}{\tau_{j}^{M F N} p_{x, k}^{\beta}}\right)
$$

From equation (14), the more restrictive the rules of origin are for intermediate input sourcing the higher the zero-profit cutoff for exporting under the PTA. It can also be seen in equation (14) that the higher the unrestricted minimum price of the intermediate input $\left(p_{x, k}\right)$, the lower the zero profit cutoff for using the PTA. The intuition here is that if the price of the intermediate input is high the export market will be less competitive in general. Lower competition in the export market will allow firms to export products with worse attributes while using the PTA.

\subsection{Firm-level profitability}

A firm's profitability in market $j$ is determined by the revenue across all of the products it sells in the market. In order to enter market $j$, firms must pay a fixed $\operatorname{cost} F_{j}$. Only after paying $F_{j}$ do firms observe their product attributes for the market, $\lambda_{j k}$. Because product attributes are distributed independently across the continuum of products, the 


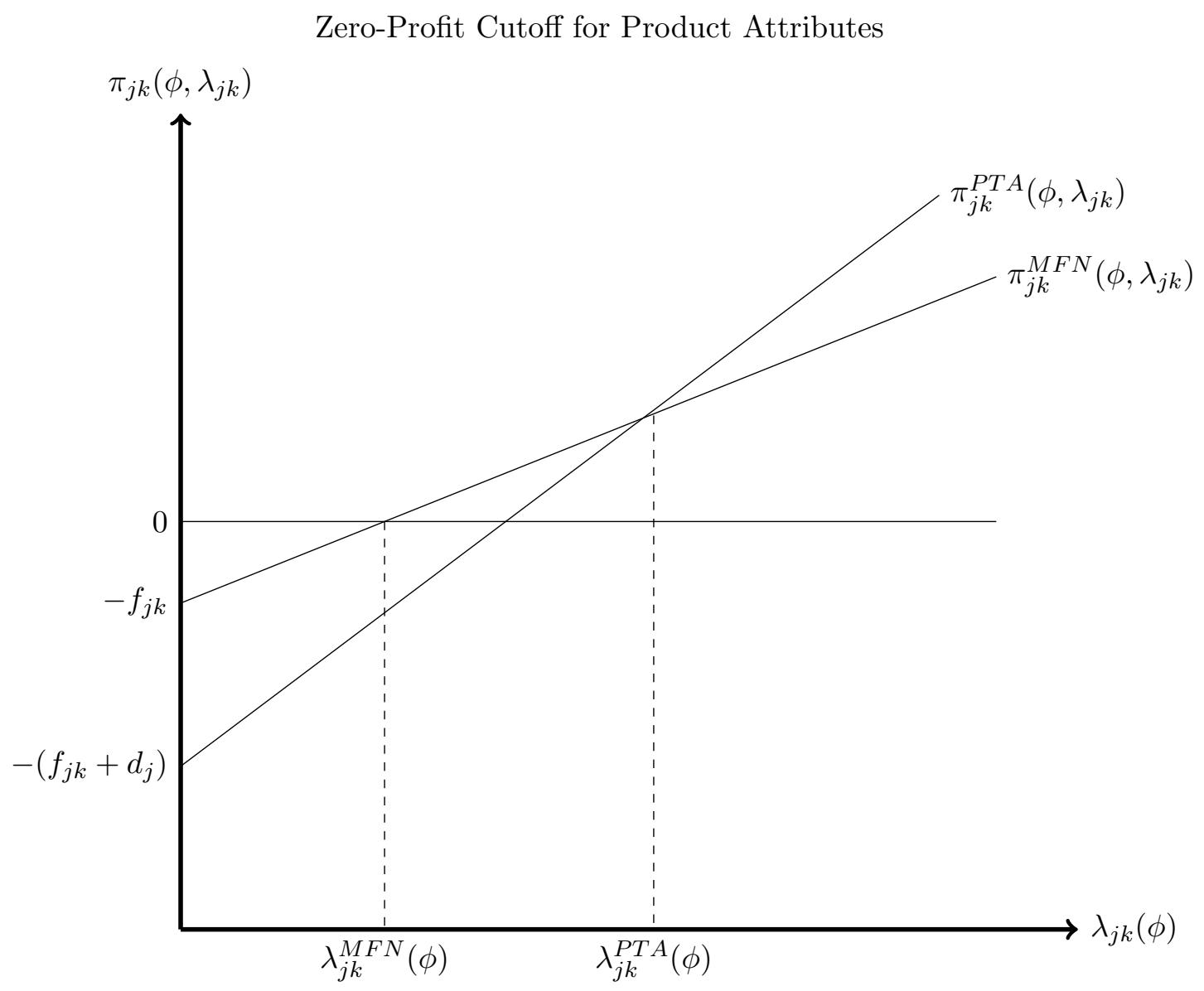

Figure 3: This figure displays the zero-profit cutoffs for product attributes, described by equations (12) and (13). 
law of large numbers implies that the expected revenue across the continuum of products is equal to the expected revenue for each product. The expected profit for each product $k$ exported to country $j$ is equal to the probability of drawing a value of product attributes above either $\lambda_{j}^{M F N}(\phi)$ or above $\lambda_{j}^{P T A}(\phi)$, multiplied by the expected profit $\left(\pi_{j}^{M F N}\right.$, or $\left.\pi_{j}^{P T A}\right)$, conditional on supplying the product. A firm's expected profit in each market $j$ is given by:

$$
\begin{array}{r}
\Pi_{j}(\phi)=\int_{\lambda_{j k}^{M F N}(\phi)}^{\lambda_{j k}^{P T A}(\phi)}\left[r_{j k}^{M F N}\left(\phi, \lambda_{j k}(\phi)\right)-\sigma f_{j k}\right] z(\lambda) d \lambda+ \\
\int_{\lambda_{j k}^{P T A}(\phi)}^{\infty}\left[r_{j k}^{P T A}\left(\phi, \lambda_{j k}(\phi)\right)-\sigma\left(f_{j k}+d_{j}\right)\right] z(\lambda) d \lambda-F_{j}
\end{array}
$$

The higher a firm's ability, the higher the probability of drawing a value of product attributes that is attractive enough to supply the product to country $j$ while invoking origin $\left[1-Z\left(\lambda_{j k}^{P T A}(\phi)\right)\right]$. This is because high overall ability can make up for low product attributes in the product-level profit equations. The probability that a firm with ability $\phi$ will be able to profitably supply a product to country $j$ without invoking origin is given by $\left[Z\left(\lambda_{j k}^{P T A}(\phi)\right)-Z\left(\lambda_{j k}^{M F N}(\phi)\right)\right]$. Thus, similar to what is shown in Demidova et al (2012), there is endogenous sorting across firms between those that export under the PTA and those that do not. Given that the expected profit from exporting is increasing in firm ability, there exists some level of ability at which the expected profit is equal to zero:

$$
\Pi_{j}\left(\phi^{*}\right)=0
$$

A firm with an ability above $\phi^{*}$ will pay the fixed $\operatorname{cost} F_{j}$ and observe their product attributes for market $j$ because the expected profits cover the fixed cost of market research. If a firm pays $F_{j}$ but finds that all of their product attributes are too low to be 
profitably exported, they exit without exporting any products to country $j$.

Using equations (12) and (13) for a firm of ability $\phi^{*}$, it can be shown that the zero-profit cutoff for firm ability, equation (16), can be expressed as:

$\int_{\lambda^{M F N}\left(\phi^{*}\right)}^{\lambda^{P T A}\left(\phi^{*}\right)}\left[\left(\frac{\lambda_{j k}(\phi)}{\lambda^{M F N}\left(\phi^{*}\right)}\right)^{\sigma-1}-1\right] \sigma f_{j k} z(\lambda) d \lambda+\int_{\lambda^{P T A}\left(\phi^{*}\right)}^{\infty}\left[\left(\frac{\lambda_{j k}(\phi)}{\lambda^{P T A}\left(\phi^{*}\right)}\right)^{\sigma-1}-1\right] \sigma f_{j k} z(\lambda) d \lambda=F_{j}$

The values $\lambda^{M F N}\left(\phi^{*}\right)$, and $\lambda^{P T A}\left(\phi^{*}\right)$ are implicitly defined in equation (17) as functions of fixed costs and the elasticity of substitution $(\sigma)$, and they are independent of $\phi^{*}$. These represent the minimum level of product attributes necessary to profitably export to $j$ while invoking the rules of origin and while not invoking the rules of origin.

Finally, using equations (12) and (13) the relative revenue between exporting product $k$ using the rules of origin and not using the rules of origin, for a firm of ability $\phi^{*}$, can be expressed as:

$$
\lambda^{P T A}\left(\phi^{*}\right)=\Theta \lambda^{M F N}\left(\phi^{*}\right) \quad \Theta=\left(\frac{f_{j k}+d_{j}}{f_{j k}}\right)^{\frac{1}{\sigma-1}}\left(\frac{\tau_{j}^{P T A} \bar{p}_{x, k}^{\beta}}{\tau_{j}^{M F N} p_{x, k}^{\beta}}\right)
$$

Thus, the expected profit for a firm with ability $\phi$ can be expressed as:

$$
\begin{array}{r}
\Pi(\phi)=\int_{\lambda^{M F N}\left(\phi^{*}\right)}^{\Theta \lambda^{M F N}\left(\phi^{*}\right)}\left[\left(\frac{\lambda_{j k}(\phi)}{\lambda^{M F N}\left(\phi^{*}\right)}\right)^{\sigma-1}-1\right] \sigma f_{j k} z(\lambda) d \lambda+ \\
\int_{\Theta \lambda^{M F N}\left(\phi^{*}\right)}^{\infty}\left[\left(\frac{\lambda_{j k}(\phi)}{\Theta \lambda^{M F N}\left(\phi^{*}\right)}\right)^{\sigma-1}-1\right] \sigma f_{j k} z(\lambda) d \lambda-F_{j}
\end{array}
$$

\subsection{Rules of Origin Liberalization}

In this section, I show how liberalizing the rules of origin affects between-firm reallocation of exports, and within-firm reallocation of product-level exports. 
Proposition 1: Rules of origin liberalization results in entry of new firms into the export market.

Proof: See appendix

Liberalizing the rules of origin reduces $\bar{p}_{x, k}$, and thus results in a reduction in $\Theta$, as can be seen in equation (18). Equation (19) shows how a reduction in $\Theta$ changes the zero profit cutoff for firm ability, and as a result, $\phi^{*}$. First, reducing $\Theta$ results in the expected profits from exporting without the rules of origin falling, as the upper limit of the first integral falls. The reduction of $\Theta$ also results in the expected profits from exporting with the rules of origin increasing because the lower limit of the second integral falls. Further, the revenue from exporting under the rules of origin increases as well, as the term $\frac{\lambda_{j k}(\phi)}{\Theta \lambda^{M F N}\left(\phi^{*}\right)}$ increases as $\Theta$ falls. Thus, given constant fixed costs, the overall effect of a rules of origin liberalization is an increase in expected profits. An increase in expected profits means lower productivity firms will be willing to pay the entry cost $F_{j}$. Therefore, liberalizing the rules of origin results in entry of lower productivity firms. In the appendix, I show this for the special case of Pareto distributed product attributes.

Proposition 2: Rules of origin liberalization results in an increase in the range of products that incumbent firms export to country $j$.

To see this, the zero-profit condition for product attributes of a firm with productivity $\phi$ and the same cutoff for a firm of ability $\phi^{*}$ can be expressed as:

$$
\begin{aligned}
\lambda_{j k}^{M F N}(\phi) & =\frac{\phi^{*}}{\phi} \lambda_{j k}^{M F N}\left(\phi^{*}\right) \\
\lambda_{j k}^{P T A}(\phi) & =\frac{\phi^{*}}{\phi} \lambda_{j k}^{P T A}\left(\phi^{*}\right)
\end{aligned}
$$

The fall in $\phi^{*}$ that results from the rules of origin liberalization decreases the zero profit cutoffs for product attributes for incumbent firms. Lower values of $\phi^{*}$ mean the average rival's products are less attractive, thus product market competition falls. Since 
the terms $\lambda_{j k}^{P T A}\left(\phi^{*}\right)$ and $\lambda_{j k}^{M F N}\left(\phi^{*}\right)$ are implicitly defined as fuctions of the fixed costs and elasticity of substitution, as show in equation (17), they are independent of $\phi^{*}$. As $\lambda_{j k}^{M F N}(\phi)$ falls, some products that were not profitable to export prior to the rules of origin change become profitable to export. Similarly, as $\lambda_{j k}^{P T A}(\phi)$ falls, the firm is able to export a wider range of its products using the rules of origin.

Proposition 3: Rules of origin liberalization results in an increase in product-level revenue for products sold under the PTA for incumbent firms, but does not change the product-level revenue for firms exporting without invoking the rules of origin.

This can be seen directly from the firm-product level revenue functions. A reduction in $\bar{p}_{x, k}$ increases the revenue for firms exporting product $k$ under the rules of origin because $\sigma>1$. For firms exporting $k$ without invoking the rules of origin, a change in $\bar{p}_{x, k}$ has no effect on revenue. Higher productivity firms will export product $k$ using the rules of origin, thus product-level revenue should increase more for high productivity firms. The increase in product-level revenue for high ability firms outweighs the lack of change in product-level revenue for low ability exporters, thus the average product-level revenue for incumbent exporters will increase.

\section{Empirical framework}

In this section, I describe the data and outline the empirical framework used to evaluate the model's predictions.

\subsection{Data and Summary Statistics}

The main data source used in this project comes from The Bangladesh National Bureau of Revenue (NBR). ${ }^{14}$ This panel data set contains information on the universe of export transactions by Bangladeshi firms. Firm-level export value, export weight, and export

\footnotetext{
${ }^{14}$ Link to the data set, provided by the International Growth Center: https://www.theigc.org/country/bangladesh/data/
} 
destination are included in the data set, as is the of day the shipment at the HS8-digit product level. I collapse the data to the annual level, as the change in the rules of origin occurred on January 1st 2011. In the appendix of this paper, I show the results are very similar when working with quarterly data. ${ }^{15}$ The sample used in this study covers transactions between 2008 to 2013, which allows me to focus on the relevant time period and include three pre-treatment years (2008-2010), and three post-treatment years (2011-2013). Finally, I focus specifically on the change from a double-transformation to a single-transformation rule of origin, which only applied to exporters of apparel. Apparel products are defined as exports in HS heading 61 (Articles Of Apparel And Clothing Accessories, Knitted Or Crocheted), and HS heading 62 (Articles Of Apparel And Clothing Accessories, Not Knitted Or Crocheted (woven)). There are 243 unique HS8-digit products in these two categories. Over the sample time period, the EU accounts for roughly $50 \%$ of annual export revenue. ${ }^{16}$

Bangladeshi apparel firms tend to be multi-product firms. Roughly $99 \%$ of firms produce more than one product. Firm-level output is highly skewed towards its top product, as shown in Table 3. The table shows information for firms that produce between one and 10 products, and displays the share of total output attributed to each product sold, descending from the firm's largest to tenth largest product. As is evident from the table, the average output share of the largest product much larger than the next largest product.

A more detailed breakdown of the data is presented in Table 4. The table is broken into two panels, one that displays the summary statistics for woven apparel products and one that displays the summary statistics for knitted apparel products. Averages and

\footnotetext{
${ }^{15} \mathrm{I}$ also examine the changes in monthly export revenue around the time of the policy change. I do not see evidence of a substantial amount of anticipation of the policy change by exporting firms. See Figure A1, in the Appendix.

${ }^{16}$ While I do not have access to firm-level import data, I show in the appendix that aggregate imports of woven textiles do respond to the policy change. Using data on woven and knitted textile imports into Bangladesh from the COMTRADE database, I find evidence that imports of woven textiles from China increase following the revision to the rules of origin. Similarly, I find evidence that imports of woven textile from other LDC countries fall dramatically post rules of origin revision.
} 
Table 3: Within-firm quantity share by product

\begin{tabular}{|c|c|c|c|c|c|c|c|c|c|c|c|}
\hline & & \multicolumn{9}{|c|}{ Number of Products Sold by Firm } & \multirow[b]{2}{*}{10} \\
\hline & & 1 & 2 & 3 & 4 & 5 & 6 & 7 & 8 & 9 & \\
\hline \multirow{10}{*}{ 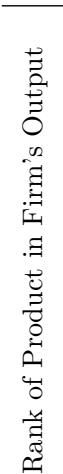 } & 1 & 1.000 & 0.805 & 0.738 & 0.692 & 0.665 & 0.638 & 0.616 & 0.596 & 0.568 & 0.554 \\
\hline & 2 & & 0.193 & 0.196 & 0.197 & 0.193 & 0.192 & 0.189 & 0.188 & 0.191 & 0.186 \\
\hline & 3 & & & 0.064 & 0.079 & 0.083 & 0.086 & 0.089 & 0.093 & 0.096 & 0.095 \\
\hline & 4 & & & & 0.031 & 0.040 & 0.046 & 0.050 & 0.053 & 0.056 & 0.059 \\
\hline & 5 & & & & & 0.018 & 0.025 & 0.030 & 0.032 & 0.036 & 0.039 \\
\hline & 6 & & & & & & 0.011 & 0.017 & 0.020 & 0.024 & 0.026 \\
\hline & 7 & & & & & & & 0.008 & 0.012 & 0.015 & 0.018 \\
\hline & 8 & & & & & & & & 0.006 & 0.009 & 0.012 \\
\hline & 9 & & & & & & & & & 0.005 & 0.007 \\
\hline & 10 & & & & & & & & & & 0.004 \\
\hline
\end{tabular}

The columns of the table report the number of products sold by the firm, while the rows display the share of firm-level output for each product. The rows are in descending order of product rank in output share.

standard deviations are shown in the table. The statistics in the table are calculated for 2010, the year prior to the change in the rules of origin. The easiest market for Bangladeshi apparel firms to enter is the market for knitted apparel in the EU. This is due to the reduced tariff rates faced by LDCs in the EU relative to the rest of the world, and due to the relative ease of producing knitted textiles. The table shows that average annual export revenue is highest for knitted products sold in the EU. The competition in knitted products sold in the EU is also highlighted by the number of firms per product, which is highest in this segment of the market. Across all segments of the market, firms export between 4 and 7 products.

\subsection{Endogeneity concerns and the triple-difference estimator}

A major threat to the identification of the effect of the rules of origin revision in the EU stems from the potential endogenous nature of the policy change itself. For example, EU policy makers may have foresaw an increase in demand for apparel products from LDCs for EU consumers and responded by revising the rules of origin for these products. As 
Table 4: Summary statistics

\begin{tabular}{lcccc}
\hline & EU Average & ROW Average & Overall Average & Obs \\
\hline \hline Woven & & & & \\
Firm-level revenue & 922.7 & 1131.2 & 1033.2 & 3887 \\
& {$[2358.7]$} & {$[3204.3]$} & {$[2839.7]$} & \\
Products per firm & 5 & 5 & 5 & 4407 \\
& {$[7]$} & {$[10]$} & {$[9]$} & \\
Firms per product & 84 & 105 & 95 & 240 \\
& {$[252]$} & {$[296]$} & {$[274]$} & \\
Knit & & & & \\
Firm-level revenue & 1319.8 & 428.8 & 836.6 & 5528 \\
& {$[3182.2]$} & {$[1249.9]$} & {$[2382.8]$} & \\
Products per firm & 7 & 4 & 5 & 6071 \\
& {$[8]$} & {$[7]$} & {$[8]$} & \\
Firms per product & 167 & 121 & 144 & 223 \\
& {$[605]$} & {$[466]$} & {$[539]$} & \\
\hline \hline
\end{tabular}

This table displays the summary statistics for the sample. These statistics are calculated in 2010, the year prior to the rules of origin change. Woven products refers to exports from HS heading 62, and knitted products refer to exports from HS heading 61. EU Exports refers to exports to EU member countries. Means are presented in the table, with standard deviations in brackets below. Firm-level revenue is resported in 100,000 Bangladeshi Taka. 
a result, any change in LDC exports of apparel products to the EU may be driven by underlying changes in economic conditions or demand rather than the revision the to rules of origin. In this situation, a difference-in-difference estimator, exploiting variation in export destination before and after the policy change, will not recover an unbiased estimate of the effect of the policy change.

In order to control for potential destination-specific demand shocks, I exploit additional variation in the cost of producing textiles. As discussed earlier in this paper, the double-transformation policy was particularly constricting for woven apparel products due to the capacity constraints in the woven textile production industry. I use a triple-difference approach, exploiting variation in input-cost differentials across woven and knitted apparel and export destination, before and after the EU policy change. With this method, I am able to control for country-specific demand shocks. Given the global nature of fashion trends, if woven apparel demand increased in the EU there was likely an increase in demand for woven apparel in other import destinations as well. Thus, product-specific shocks are also controlled for in the triple-difference estimator.

Figure 4 displays the trends in woven and knitted apparel export revenue, to EU and the rest of the world (ROW), over the sample time period. The solid lines represent the geometric mean annual firm-level export revenue for woven apparel exports. The dashed lines represent the geometric mean annual firm-level export revenue for knitted apparel exports. The gray lines indicate exports to the ROW, while black lines indicate exports to the EU. The vertical line at Year $=2011$ marks the year in which the rules of origin for EU imports were changed. As is clear from the figure, exports of both types of products sold to both destinations are trending up over the sample time frame. This could be driven by a number of factors. For example, the recovery from the great recession occurred within the sample time frame. Thus, the upward trend in the sales of all apparel products, to both destinations could be a response to higher incomes in the later half of the sample. The growth in exports of all products to all destinations over 
this time period indicates that Bangladeshi apparel firms were not capacity constrained. If firms faced capacity constraints, exports of other products to other markets would decline following the rules of origin liberalization as firms shifted their focus to woven products sold to the EU. I examine this later in the empirical section of the paper.

Figure 5 displays the trends in the difference between the solid lines in Figure 4, and the difference between the dashed lines in Figure 4 over time. Notably, the difference trends in exports of knitted products does not appear to respond to the change in the rules of origin in 2011. The identifying assumption needed in order for the estimates produced by the triple-difference estimator to be consistent is that the pre-2011 trends between these two groups should not be statistically different from each other. In other words, the change in the difference between knitted garment exports to the EU and ROW should mimic the change in the difference of woven garments in the absence of the rules of origin revision. While this appears to be the case in Figure 5, in section $5.4 \mathrm{I}$ examine the validity of the identifying assumption more rigorously using an event-study framework.

\section{Empirical results}

In this section, I present evidence of the effects of the rules of origin revision on Bangladeshi apparel exporter's margins of trade. I first show the effect on firm-product export revenue, followed by evidence of the effect on two extensive margins of trade; the within-firm product level extensive margin, and the between-firm extensive margin. For each margin of trade, I provide evidence of the robustness of the results to increasingly demanding sets of fixed effects that control for a number of potential confounding factors. I examine the robustness of the identifying assumption using an event-study framework, as well as falsification exercises. 
Trends in Export Revenue

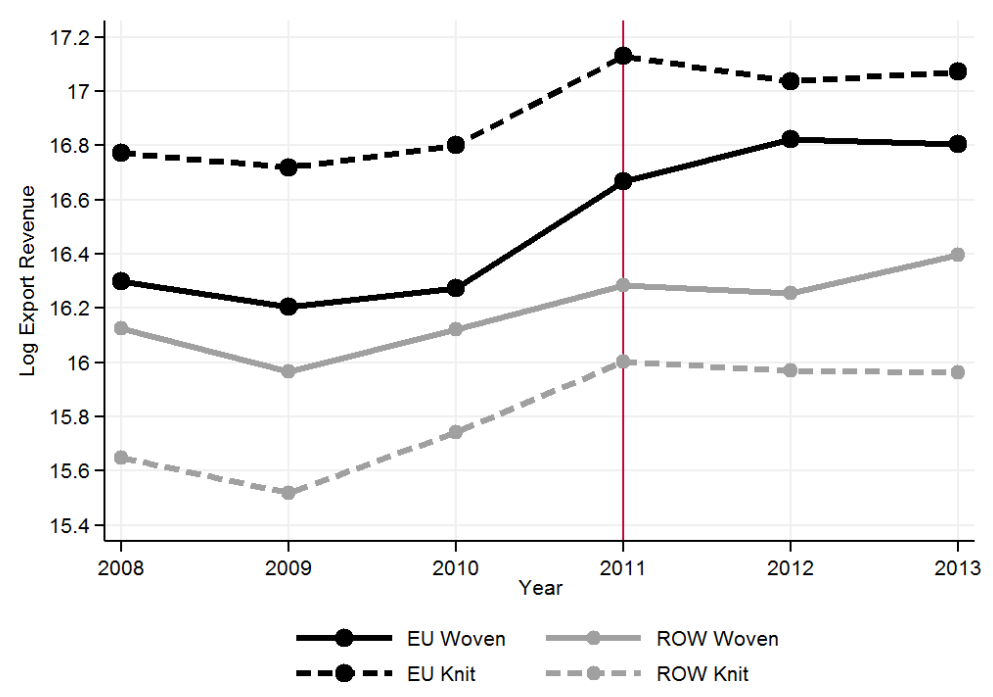

Figure 4: This figure shows the trends in log average export value of firm-level exports to the EU and ROW in knit and woven apparel over time. The solid lines represent woven apparel exports (HS 62), while the dashed lines represent knitted apparel exports (HS 61). The change in the Rules of Origin for EU countries (from double- to singletransformation) occurred on January 1st, 2011 and is shown by the vertical line. 
Differenced Trends in Export Revenue

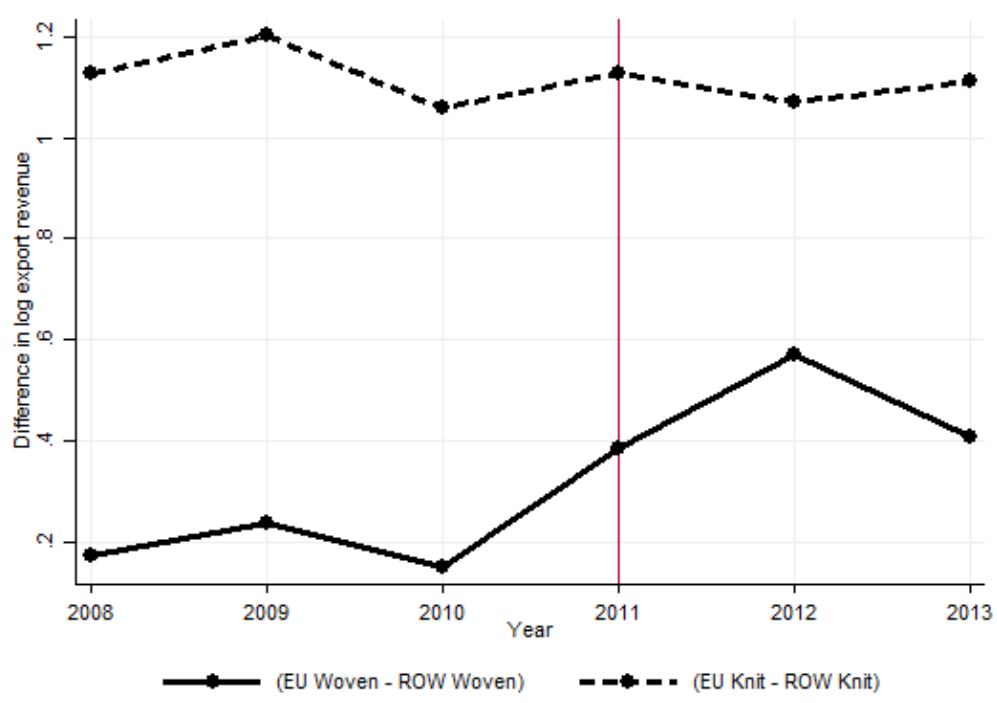

Figure 5: This figure shows trends in the difference between the average export value of woven goods to EU countries and to the ROW (solid line) and the difference between average export value of knitted goods to EU countries and the ROW (dashed line). The change in the Rules of Origin for EU countries (from double- to single-transformation) occurred on January 1st, 2011 and is shown by the vertical line. 


\subsection{Firm-product revenue}

I begin by examining the effect of the liberalization of the rules of origin governing the access to the EU's EBA arrangement on product level export revenue. To do this, I construct three indicator variables: (i) an indicator for whether the product is woven (HS 62), (ii) an indicator for whether the product is exported to the EU, and (iii) an indicator for whether the product was exported after the policy change in 2011. I then regress the log of export revenue on a triple interaction of these three indicators, along with a robust set of fixed effects. The triple-interaction term conducts the triple-difference estimate discussed earlier. The empirical specification is as follows:

$$
\ln \left(r_{i j k t}\right)=\beta_{1}\left(E U_{j} * \text { Woven }_{k} * \text { Post }_{t}\right)+\phi_{i k}+\lambda_{j k}+\delta_{j t}+\gamma_{k t}+u_{i j k t}
$$

Here, $r_{i j k t}$ is the reported export revenue from firm $i$, product $k$ (HS 8 level), in destination $j$ (EU or the ROW), in year $t .{ }^{17}$ The parameter $\beta_{1}$ captures the tripledifference effect. Equation (21) based on equations (8) and (10) in section 3.4. Although the reduced-form nature of the empirical model does not allow me to directly estimate model parameters, equation (21) does allow me to test the validity of the model's predictions. I control flexibly for firm-product heterogeneity $\left(\phi_{i k}\right)$ using firm-product fixed effects, which accounts for firm ability and the average level of a firm's product attributes. The inclusion of destination-product fixed effects controls for the product attributes parameter, destination $j$ 's average expenditure on product $k$, and the $j k$ price index discussed in section 3. It also controls for the $E U_{j} *$ Woven $_{k}$ interaction term in a highly flexible manner. I control for destination-year and product-year fixed effects to account for the $E U_{j} *$ Post $_{t}$, and Woven $k *$ Post $_{t}$ interaction. Using interacted fixed effects to control for double-interaction terms in a triple-difference-in-differences model is done in Frazer and Van Biesebroeck (2010), where it is referred to as the "unrestrictive"

\footnotetext{
${ }^{17}$ The results using PPML estimation, rather than a log-linear model are similar in magintude and statistical significance.
} 
Table 5: Firm-Product Export Revenue

\begin{tabular}{lcc|ccc}
\hline \hline & \multicolumn{2}{c}{ All Firms } & \multicolumn{3}{c}{ Incumbents } \\
& $(1)$ & $(2)$ & $(3)$ & $(4)$ & $(5)$ \\
\hline \hline$U_{j} *{\text { W } \text { oven }_{k} * \text { Post }_{t}}$ & $0.14^{* * *}$ & $0.16^{* * *}$ & $0.17^{* * *}$ & $0.17^{* * *}$ & $0.18^{* * *}$ \\
& $(0.048)$ & $(0.052)$ & $(0.051)$ & $(0.051)$ & $(0.053)$ \\
& & & & & \\
Observations & 182,094 & 136,700 & 83,159 & 80,711 & 80,703 \\
R-squared & 0.309 & 0.620 & 0.617 & 0.616 & 0.710 \\
Firm FE & $\mathrm{X}$ & & & & \\
Dest-Prod FE & $\mathrm{X}$ & $\mathrm{X}$ & $\mathrm{X}$ & $\mathrm{X}$ & $\mathrm{X}$ \\
Dest-Year FE & $\mathrm{X}$ & $\mathrm{X}$ & $\mathrm{X}$ & $\mathrm{X}$ & $\mathrm{X}$ \\
Prod-Year FE & $\mathrm{X}$ & $\mathrm{X}$ & $\mathrm{X}$ & $\mathrm{X}$ & $\mathrm{X}$ \\
Firm-Prod FE & & $\mathrm{X}$ & $\mathrm{X}$ & $\mathrm{X}$ & \\
Firm-Prod-Dest FE & & & & & $\mathrm{X}$ \\
\hline \hline
\end{tabular}

This table displays the results from estimating equation (21). The first four columns use all firms in the data. Columns (4) and (5) restrict the sample to contain only multiproduct firms. Errors allow for clustering at the HS8 product level in all columns.

triple-difference model. Finally, to account for potential correlation in error error term, I allow for clustering at the product level.

Table 5 displays the results of estimating equation (21). Starting with column (1), I estimate the rules of origin revision increased firm-product level exports by roughly 15\%. The effect size is calculated using the methods outlined in Kennedy (1981) for interpreting coefficients on dichotomous variables with a logged dependent variable. ${ }^{18}$ The $17 \%$ increase, when evaluated at the 2010 average product-level export revenue (as shown in Table 4) is roughly equivalent to an increase in export revenue of 16 million Bangladeshi Taka, or $\$ 233,000 .{ }^{19}$ The results in columns (1) and (2) are estimated using a sample of all firms. This includes firms that entered the market after the policy change, as well as firms that were already exporting product $k$ to destination $j$ prior to the policy

\footnotetext{
${ }^{18}$ The interpretation of the coefficient on a dichotomous regressor on a logged dependent variable is done using the methods in Kennedy (1981). This involves calculating $[\exp (\hat{\beta}) / \exp (0.5(\hat{V}(\hat{\beta}))-1]$ where $\hat{V}(\hat{\beta})$ is the estimated variance of $\hat{\beta}$.

${ }^{19}$ The exchange rate of Bangladeshi Taka to USD on December 31st, 2010 was 0.0142 to 1. This makes the export revenue gain equal to roughly $\$ 223,000$.
} 
change.

Columns (3) through (5) present the results of estimate equation (21) using a sample of incumbent firms only. Here, an incumbent is defined as a firm that exported the same product to the same destination during the double-transformation period (pre-2011) and during the single-transformation period (post-2011). This sample excludes brand new exporters, that only entered the export market post-2011, and exiters who left the market after 2011. Column (3) presents the results for all such incumbent firms, while column (4) presents the results for multi-product incumbents. Multi-product firms are defined as firms that export at least two products each year. In both cases, the effect of the rules of origin liberalization on firm-product level export revenue was an $18 \%$ increase.

Finally, the last column of Table 5 displays the results of estimating equation (21) using a sub-sample of firms that exported the same product, to the same destination, each year. This is the balanced panel. I then control for firm-product-destination fixed effects, rather than firm-product and destination-product fixed effects. Using this definition of incumbent firms and this robust set of fixed effects, the estimate of $\beta_{1}$ in equation (21) uses variation within a firm-product-destination group over time, and excludes any firmproducts, or product-destination pairs that entered or exited within this time frame. I estimate moving to a single-transformation policy resulted in a $19.5 \%$ increase in export revenue for this sample of firms.

\subsection{Product-level extensive margin}

Next, I analyze the effect of the rules of origin revision on the number of products sold by incumbent firms. Here, incumbents are defined as firms that exported any product to a given destination in the pre-2011 and post-2011 periods.

I collapse the data to the firm-destination-year level for this analysis. Then for each firm-destination-year group, I count the number of exported woven and knitted 
products. I then impute zeros for all missing firm-destination-year pairs. In other words, if a firm-destination-year pair is missing from the collapsed sample, I assume that no products were exported from the firm to the destination in that year. This assumption is reasonable as the data set contains the universe of firm-level transactions. This is done in order to estimate the following non-linear regression model using a (pseudo) Poisson maximum likelihood estimator. ${ }^{20}$ The Poisson model requires the potential for zero outcomes, and given the count nature of the dependent variable, this model best describes the data generating process. ${ }^{21}$ The empirical model is as follows:

$$
\operatorname{NumProd}_{i j k t}=\exp \left\{\beta_{1} E U_{j} * \text { Woven }_{k} * \text { Post }_{t}+\phi_{i j}+\lambda_{j k}+\delta_{j k t}+\gamma_{k t}+\epsilon_{i j k t}\right\}
$$

where, NumProd ijkt $_{\text {is }}$ the number of woven or knit products $(k)$ exported by firm $i$, to destination $j$, in year $t . \epsilon_{i j k t}$ is an error term, which I allow to cluster at the firm level. I also test cluster bootstrapped standard errors, as is recommended by Puhani (2012). The subscript $k$ in equation (22) represents either woven or knit, rather than the HS 8 level product. Thus, the dependent variable is the expected log count of the number of HS 8 level products, within an HS 2 heading (HS 61 is knit, HS 62 is woven). I control for firm-destination fixed effects, destination-year fixed effects, product-year fixed effects, and destination-product fixed effects.

The results of estimating equation (22) are presented in Table 6. Columns (1) present the results when using all incumbents, and columns (2) and (3) present the results when using only multi-product incumbents in the estimating sample. In all columns, the

\footnotetext{
${ }^{20}$ I use the pseudo Poisson estimator because it does not require the underlying distribution to strictly follow the Poisson distribution. See Santos Silva and Tenreyro (2006)

${ }^{21}$ The results from the sample ignoring zeros are very similar in magnitude and statistical significance. The reason for including zeros is to better capture the data generating process. It is possible to estimate a zero-truncated Poisson (ZTP) regression model, however, the distributional assumption that a zero value of the dependent variable cannot occur does not reflect the true data generating process, making this model relatively unattractive for the purposes here. That being said, the results are similar when a ZTP model is used rather than a Poisson model.
} 
Table 6: Number of products per incumbent firm

\begin{tabular}{lccc}
\hline \hline & $(1)$ & $(2)$ & $(3)$ \\
\hline \hline EU $_{j} *$ Woven $_{k} *$ Post $_{t}$ & $0.09^{* * *}$ & $0.09^{* * *}$ & $0.09^{* * *}$ \\
& $(0.029)$ & $(0.029)$ & $(0.029)$ \\
Constant & $2.19^{* * *}$ & $2.19^{* * *}$ & $2.26^{* * *}$ \\
& $(0.003)$ & $(0.035)$ & $(0.035)$ \\
& & \\
Errors & cluster & bootstrap & bootstrap \\
Observations & 36,781 & 36,781 & 31,569 \\
\hline \hline \multicolumn{4}{c}{$* * * \mathrm{p}<0.01,{ }^{* *} \mathrm{p}<0.05,{ }^{*} \mathrm{p}<0.1$} \\
\end{tabular}

This table displays the results from estimating equation (22). All columns include firmdestination, destination-year, product-year, and destination-product fixed effects. The first two columns use a sample of all incumbent firms, while column (3) restricts the estimating sample to multi-product incumbents. Errors allow for clustering at the firm level in the first column, and are cluster bootstrapped (with 1,000 replications) at the firm level in the second two columns.

revision of the rules of origin policy increased the expected log counts of the number of products sold by incumbents by 0.09 . When using the methods described in Sang et al. (2017) this estimate corresponds to roughly a $9 \%$ increase in the number of products exported. $^{22}$ When evaluated at the pre-2011 mean, this is equivalent to an increase of roughly 0.5 products. To estimate the precision of the estimates in Table 6 , I use the methods described in Puhani (2012) where bootstrapping is recommended for inference in non-linear difference-in-difference models. Column (2) and (3) show the results when errors are cluster bootstrapped at the firm-level.

\subsection{Firm-level extensive margin}

Next, I estimate the effect of the rules of origin revision on firm-level entry. To do this, I begin by counting the number of firms exporting at each HS 8 level product to the EU and the ROW. I then create a balanced panel for all product-destination pairs in each

\footnotetext{
${ }^{22}$ The magnitude of the effect of interacted dichotomous variables in the PPML model is done using the methods outlined in Shang et al., (2017), or as the difference-in-difference-in-semielasticities.
} 
Table 7: Number of Firms

\begin{tabular}{|c|c|c|c|}
\hline & $(2)$ & $(3)$ & $(4)$ \\
\hline EU $_{j} *$ Woven $_{k} *$ Post $_{t}$ & $\begin{array}{c}0.08^{* *} \\
(0.031)\end{array}$ & $\begin{array}{l}0.08 * * \\
(0.034)\end{array}$ & $\begin{array}{c}0.08^{*} \\
(0.045)\end{array}$ \\
\hline Constant & $\begin{array}{c}6.60^{* * *} \\
(0.003)\end{array}$ & $\begin{array}{c}6.60^{* * *} \\
(0.400)\end{array}$ & $\begin{array}{c}6.58^{* * *} \\
(0.179)\end{array}$ \\
\hline errors & cluster & bootstrap & bootstrap \\
\hline Observations & 2,544 & 2,544 & 2,460 \\
\hline
\end{tabular}

This table displays the results from estimating equation (23). All columns include destination-product, destination-year, and product-year fixed effects. The first column use a sample of all incumbent firms, while column (2) and (3) restrict the estimating sample to multi-product incumbents. Errors allow for clustering at the HS- 8 product level in the first column, and are cluster bootstrapped at the product level in the second two columns.

year, imputing zeros in situations where no firm exported a product to the destination in a given year. Most products have at least one firm exporting them to the destination market, there are only 44 product-destinations that do not appear in each year. This is done in order to estimate a Pseudo-Poisson model, where zero outcomes are required. The empirical model is as follows:

$$
\text { NumFirms }_{j k t}=\exp \left\{\beta_{1} E U_{j} * \text { Woven }_{k} * \text { Post }_{t}+\gamma_{j k}+\delta_{k t}+\lambda_{j t}+\epsilon_{j k t}\right\}
$$

where, NumFirms $s_{j k}$ is the number of firms exporting product $k$ (HS8-level) to destination $j$ in year $t$. I include destination-product fixed effects, destination-year fixed effects, and product-year fixed effects to control for all double-interactions and dummy variables.

Table 7 presents the results of estimating equation (23). The first column present the results using all firms in the estimating sample, while the second two columns restrict 
the sample to only multi-product firms. Across the specifications in Table 7, the liberalization of the rules of origin resulted in an increase in the expected log counts of the number of firms exporting woven products to the EU by 0.08 . Using the estimates from column (2), the effect of the rules of origin liberalization corresponds to an increase of roughly seven firms. ${ }^{23}$ Standard errors presented in Table 7 either allow for clustering at the product level, or are cluster bootstrapped at the product level, as is recommended by Puhani (2012).

\section{Robustness}

In this section, I test the robustness of the results presented in the previous section. I examine the underlying assumption that there are no differential pre-trends using an event-study framework and a falsification test.

\subsection{Event-study framework}

The identifying assumption underlying the estimates presented in Tables 5, 6, and 7 is that there are no differential pre-trends. This identifying assumption is needed for both the log-linear model used to estimate product level export revenue, as well as the PPML models used to estimate equations (22) and (23). The difference between the common trends assumptions is that PPML requires a multiplicative common trend rather than a linear one (Ciani and Fisher, 2013). This means the difference between the outcome for woven products sold to the EU and the ROW prior to the rules of origin change should not be statistically different from the difference between the outcome for knitted products sold to the EU and the ROW prior to the rules of origin change.

While the identifying assumption is not testable, evidence consistent with its validity can be provided by examining the pre-treatment trends. I estimate the response of

\footnotetext{
${ }^{23}$ Again, the interpretation of these interacted effects is based on the recommendations in Shang et al (2017).
} 
product level export revenue, the number of products exported per firm, and the number of firms per exported product to the rules of origin revision using an event-study framework. Here, rather than restricting the effect of the policy change on the outcome variables to remain constant in the pre-2011 and post-2011 periods, I allow it to vary by year. The estimating equations are identical to equations (21) through (23), but all of the Post $_{t}$ indicators are replaced with indicators for each year.

$$
E\left(Y_{i j k t}\right)=f\left(\sum_{t=1}^{T} \beta_{t}\left(E U_{j} * \text { Woven }_{k} * \text { Year }_{t}\right), \Gamma_{i j k t}, u_{i j k t}\right)
$$

In equation (24), $Y_{i j k t}$ refers to either product-level export revenue (in logs), the number of firms per product, or the number of products per firm. $\Gamma_{i j k t}$ is a vector of interacted dummy variables and fixed effects. In all specifications I allow for destination-year fixed effects. In the number of firms extensive margin regression I include product-destination fixed effects, and in the number of products extensive margin and product-level intensive margin regressions I include firm-product fixed effects. The full specifications are available in Table A6 in the Appendix. The right-hand side of the equation (24) depends on the estimation procedure used. For product-level export revenue $f()$ is a linear model, while for the two extensive margin outcomes $f()$ is a non-linear model and (24) is estimated using PPML. The parameters of interested are the $\beta_{t} \mathrm{~s}$. These are the estimated triple-difference effect for each year.

The results are presented in graphical form in Figure 6. In the figure I display the estimate of the $\beta_{t}$ s from equation (24) along with the $95 \%$ confidence interval around the estimate. Each panel of the figure displays the results for a different outcome. In each panel, the year prior to the rules of origin revision is normalized to zero. As can be seen in the figure, the difference between woven exports to the EU and woven exports to the ROW is not statistically different from the difference between knitted exports to the EU and knitted exports to the ROW prior to the policy change for any outcome 

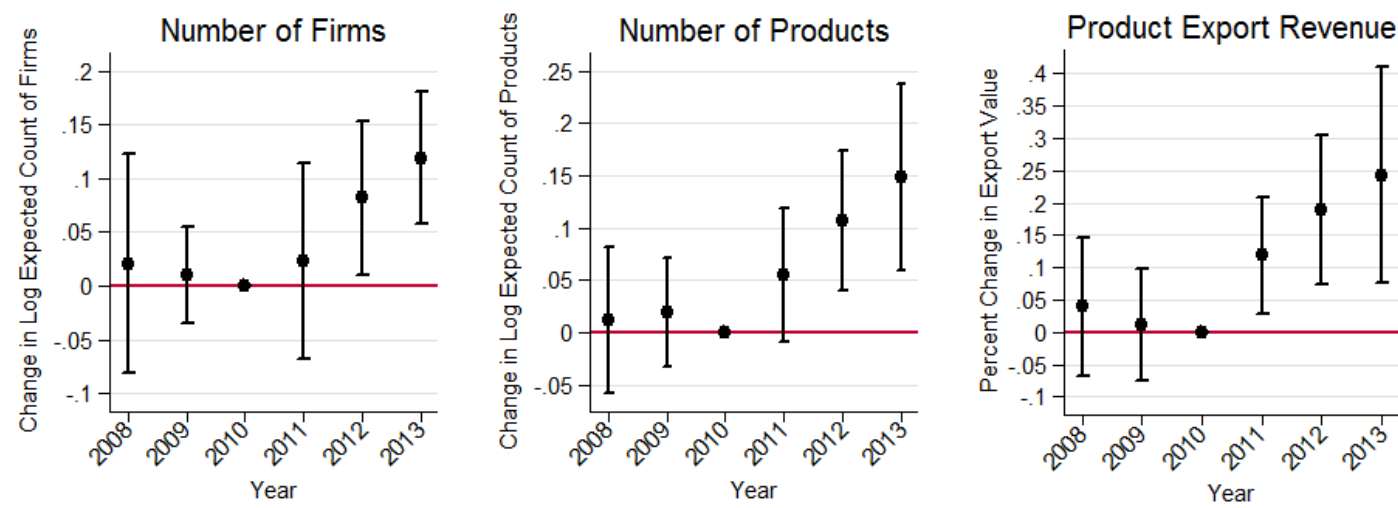

Figure 6: This figure show the estimate, and 95\% confidence interval, of the parameter on the triple-interaction term from equations (22) through (24), where the Post $_{t}$ variable has been replaced in all instances with year dummy variables. The year 2010 has been normalized to zero. Regression output is available in Table A6.

variable.

Figure 6 not only provides evidence consistent with the identifying assumption, but also shows there are dynamic effects in response to the liberalization of the rules of origin. For the entry of new firms, this is not surprising. It may take time for firms to enter due to the fixed market entry cost, associated with market research or connecting with distributors. The slow response of the number of products sold by incumbent firms may also be driven by the fixed costs of supplying individual products. Exporting new products may require learning about general product standards, or product-specific advertising, for example.

The response of firm-product level export revenue for incumbent firms is immediate. Theoretically, incumbent firms should have already paid the various fixed costs associated with exporting a given product, thus this effect of the rules of origin liberalization on product level export revenue is expected. In the Table A6, I show that the inclusion of more restrictive fixed effects does result in the effect in 2011 becoming 
statistically insignificant. One explanation for the slow response could be that there are costs associated with switching input suppliers. If it is costly to search over the set of intermediate input prices, liberalizing the rules of origin could result in incumbent firms re-optimizing where they source their inputs, and this re-optimization may take time. If some firms were exporting woven products without invoking the rules of origin, the delayed effect could be explained by the rules of origin fixed cost as well. If it takes time for firms to learn how to navigate the documentation process, the effects of a rules of origin liberalization would not result in immediate revenue gains.

\subsection{Falsification Test}

Next, I examine the robustness of the results presented in the previous sections. To do this, I conduct a falsification exercise that creates a placebo change to the rules of origin associated with the EBA in 2010. I then limit my estimating sample to the years 2008, 2009, and 2010 and re-estimate the triple difference model for all three margins. ${ }^{24}$ The value of export revenue, the number of products sold per firm, and the number of exporting firms should not respond to this placebo policy timing. Recovering a similar estimate under a placebo policy would be consistent with a failure of the parallel trends assumption.

The results of this exercise are presented in Table 8 . In all cases, the response of woven products sold to the EU under the placebo post period are not statistically different from zero at traditional levels. Furthermore, the estimates of the treatment effect under the placebo treatment are statistically different from the actual estimates. This is shown in the row titled T-stat.

\footnotetext{
${ }^{24} \mathrm{I}$ also test a placebo Post variable that takes the value of 1 if the year is 2009 , and zero otherwise. The results are very similar to what is shown in the paper.
} 
Table 8: Placebo timing

\begin{tabular}{lccc}
\hline & $(1)$ & $(2)$ & $(3)$ \\
& Intensive & Product Level Extensive & Firm Level Extensive \\
\hline EU $U_{j} *{\text { W } \text { oven }_{k} * \text { Post }_{t}}$ & -0.011 & -0.057 & \\
& $(0.051)$ & $(0.035)$ & 0.026 \\
Constant & $15.60^{* * *}$ & $2.12^{* * *}$ & $(0.028)$ \\
& $(0.004)$ & $(0.003)$ & $\left(0.41^{* * *}\right.$ \\
T-stat & 3.35 & 4.20 & 1.93 \\
& & & \\
Observations & 57,198 & 17,456 & 1,303 \\
R-squared & 0.664 & & \\
Firm-prod FE & $\mathrm{x}$ & $\mathrm{x}$ & $\mathrm{x}$ \\
Dest-prod FE & $\mathrm{x}$ & $\mathrm{x}$ & $\mathrm{x}$ \\
Dest-year FE & $\mathrm{x}$ & $\mathrm{x}$ & $\mathrm{x}$ \\
Prod-year FE & $\mathrm{x}$ & $\mathrm{x}$ & product \\
errors & product & firm & \\
\hline
\end{tabular}

This table displays the results of estimating equations the triple difference model for each outcome. Each column only uses a sample from 2008-2010, and the Post $t_{t}$ variable is redefined to take the value of 1 if the year is 2010 . T-stat presents the t-statistic of a t-test for whether the placebo coefficient is different from the actual coefficient.

\section{Additional within-firm responses}

In this section, I examine additional within-firm responses to the rules of origin liberalization. In particular, I examine whether the expansion of product scope for incumbent firms came at the expense of sales of existing products. Then I examine the potential for capacity constraints within Bangladeshi apparel exporters. Finally, I examine the response of product quality and quality-adjusted prices of products following the rules of origin revision.

\subsection{Effect by product ranking}

The model predicts that they entry of new firms, and new products by incumbent firms, reduces the average product market competition because the products that are introduced are less desirable than the products already in the market prior to the rules of 
origin revision. As a result, incumbent firms are able to introduce new products without cannibalizing sales of their existing products. I show that incumbent firms introduced new products in section 5.2. Here, I show that the introduction of new products did not reduce the export revenue of exiting products sold by these firms.

I first calculate each products share of firm output prior to 2011. I calculate product share within HS2-destination levels, allowing me to determine each firm's best selling woven and knit product to the EU and the ROW prior to the rules of origin change. Next, I estimate equation (21) using sub-samples containing only the best selling product, second best selling product, and so on. The results of this exercise are presented in Table 9.

Table 9: Sales of existing products by rank

\begin{tabular}{lcccccc}
\hline \hline & $(1)$ & $(2)$ & $(3)$ & $(4)$ & $(5)$ & $(6)$ \\
Pre-2011 product rank: & $1^{\text {st }}$ & $2^{\text {nd }}$ & $3^{\text {rd }}$ & $4^{\text {th }}$ & $5^{\text {th }}$ & $6^{\text {th }}$ and above \\
\hline \hline \multirow{2}{*}{ EU $U_{j} *{\text { W } \text { oven }_{k} * \text { Post }_{t} *}$} & $0.25^{* * *}$ & $0.39^{* * *}$ & $0.30^{* *}$ & $0.31^{* *}$ & $0.40^{*}$ & 0.18 \\
& $(0.073)$ & $(0.104)$ & $(0.147)$ & $(0.153)$ & $(0.208)$ & $(0.145)$ \\
Constant & $16.87^{* * *}$ & $16.10^{* * *}$ & $15.72^{* * *}$ & $15.47^{* * *}$ & $15.30^{* * *}$ & $15.15^{* * *}$ \\
& $(0.007)$ & $(0.011)$ & $(0.017)$ & $(0.019)$ & $(0.025)$ & $(0.016)$ \\
Observations & & & & & & \\
R-squared & 29,100 & 17,307 & 10,043 & 6,584 & 4,283 & 11,724 \\
\hline \hline
\end{tabular}

This table presents the results of estimating equation (21) using sub-samples of products within incumbent firms. Each column represents the effects of the rules of origin revision on the firms 1st, 2nd, 3rd, 4th, 5th, and $\geq 6$ th best selling products prior to 2011 .

The first column of Table 9 shows how firms best selling products (prior to 2011) responded to the rules of origin revision. Columns (2) through (5) repeat this for products ranked two through five. The last column of the table displays the results for products ranked six and up. I group these products together because samples sizes quickly become too small when treated separately. Revenue gains for firms top four products increased by between $28 \%$ and $47 \%$, while export revenue of products ranked sixth and 
above did not increase by a statistically significant amount. ${ }^{25}$ The results indicate the export revenue of firms best-selling products did not come at the expense of lower-selling products.

\subsection{Capacity Constraints}

In the theoretical model, I assume that firms set prices for each product and destination market independently. This assumption is frequently employed in theoretical models of trade with heterogeneous firms. ${ }^{26}$ However, if firms are capacity constrained and face increasing marginal costs of production, a positive demand shock for one product may result affect sales of other products. This assumption has empirical implications as well. If Bangladeshi apparel exporters are capacity constrained, the increased demand for woven products in the EU may also affect prices, and therefore sales, of other products. The result of the triple-difference estimates may be upward biased if sales of other products fell as a result of the revision to the double-transformation rule of origin in the EU.

To examine this, I estimate the following event-study specifications for incumbent product revenue:

$$
\ln \left(r_{i j k t}\right)=\phi_{i k}+\gamma_{j k}+\delta_{j t}+\sum_{t=2008}^{t=2013} \beta_{t}\left(\text { Woven }_{k} * \text { Year }_{t}\right)+\epsilon_{i j k t}, \quad \text { if } j \neq E U
$$

and,

$$
\ln \left(r_{i j k t}\right)=\phi_{i k}+\gamma_{j k}+\delta_{k t}+\sum_{t==2008}^{t=2013} \beta_{t}\left(E U_{j} * Y_{\text {ear }}\right)+\epsilon_{i j k t}, \quad \text { if } k \neq \text { Woven }
$$

\footnotetext{
${ }^{25}$ Effect size is calculated using the methods in Kennedy (1981). This involves calculating $[\exp (\hat{\beta}) / \exp (0.5(\hat{V}(\hat{\beta}))-1]$ where $\hat{V}(\hat{\beta})$ is the estimated variance of $\hat{\beta}$.

${ }^{26}$ For example, see: Melitz (2003); Bernard, Redding, and Schott (2011).
} 
In equation (30), I estimate how sales of woven products sold to non-EU countries responded after the EU's rules of origin revision. In equation (31), I examine how the sales of knitted apparel products change in the EU after the rules of origin revision. If apparel firms are capacity constrained, the positive demand shock for woven apparel in the EU will result in a decline in sales of woven products to the ROW and/or knit products sold in the EU.

The results of estimating equations (30) and (31) are presented graphically in Figure 7. The panel on the left shows the event-study results for equation (30) and the right panel displays the results of the event-study specified in equation (31). While exports of woven products sold to non-EU countries do appear to decline following the 2011 rules of origin revision, the decline is small in magnitude and not statistically different from zero. There does not appear to be a discernable decline in the sales of knit products to the EU following the rules of origin revision either. The results here indicate that Bangladeshi apparel exporters are not capacity constrained, and that they were able to satisfy the positive demand shock for woven apparel in the EU without affecting sales of other products to other destinations.

\subsection{Prices and product quality}

Rules of origin liberalization allows final goods exporters to search over a larger set of intermediate input prices during sourcing decisions. As a result, the price of final goods fall. In this section, I explore how prices of apparel products responded to the revision of the double-transformation policy.

First, I estimate equation (21) using log price as a dependent variable. Column (1) of Table 10 shows that the rules of origin revision increased prices by roughly three percent. This is at odds with what is predicted by the theory. Even after accounting for the fact that the results in column (1) combine the effect on prices of enterants and incumbents I find that prices increase following the rules of origin revision. Column (2) presents the 

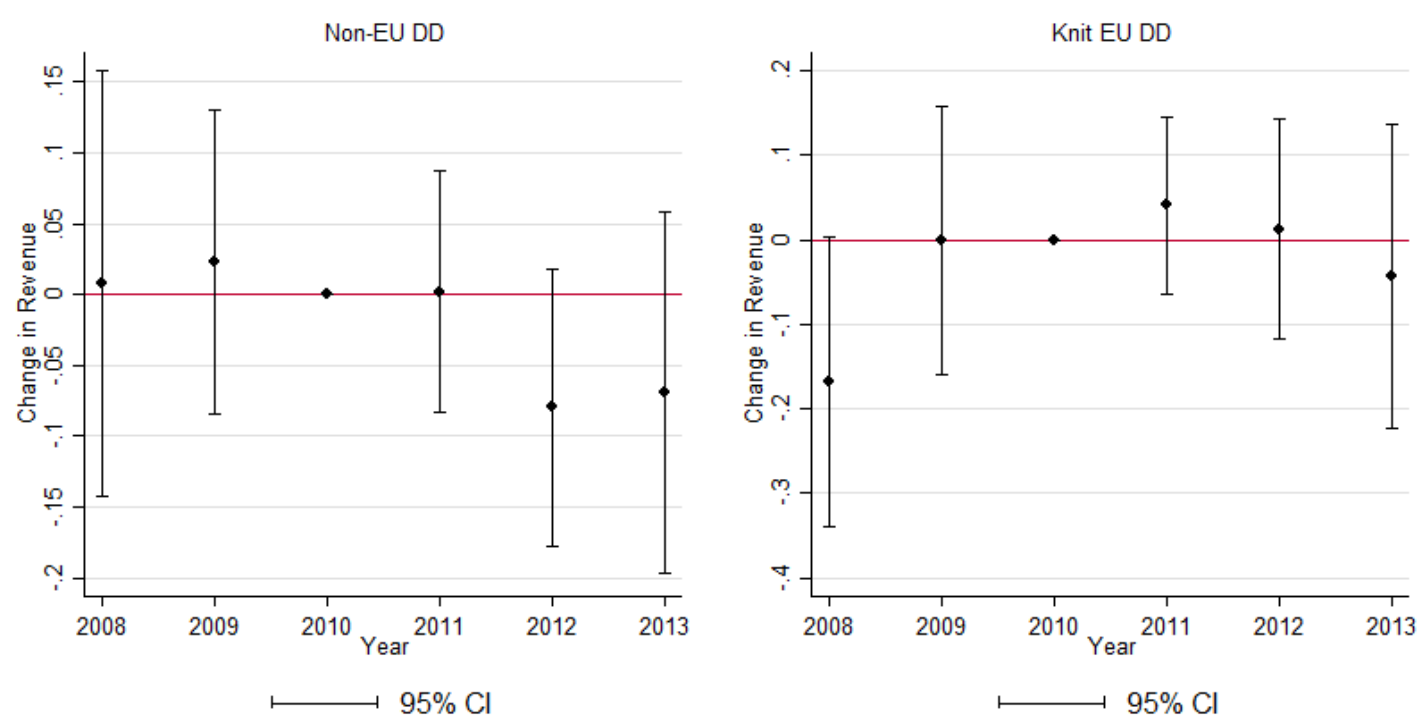

Figure 7: This figure show the estimate, and 95\% confidence interval, of the parameter on the $\beta_{t}$ 's from equations (30) through (31), where the Post $_{t}$ variable has been replaced in all instances with year dummy variables. The year 2010 has been normalized to zero.

results when using only incumbent firms.

Quality upgrading is a potential explanation for prices rising following the rules of origin revision. Firms may be able to upgrade the quality of their exported apparel products by importing higher quality textiles following the rules of origin revision. To address this, I construct a measure of product quality based on Khandelwal et al. (2013), which uses the functional form of the utility function. Equation (25) presents a slight modification to the utility function presented in section 3.2 that allows for a factor specific to product quality $q_{i j k}(\omega)$ :

$$
C_{j k}=\left[\sum_{i=1}^{J} \int_{\omega \in \Omega_{i j k}}\left(q_{i j k}(\omega) \lambda_{i j k}(\omega) c_{i j k}(\omega)\right)^{\rho} d \omega\right]^{\frac{1}{\rho}}
$$

Here, $q$ represents the part of product attributes $\lambda$ that corresponds to product quality. I take this step because $\lambda$ is a term that is more general than product quality, 
thus specifying a parameter that specifically captures quality is necessary.

The demand for product $k$, with attributes $\lambda_{j k}$ and quality $q_{j k}$, in destination $j$, from a firm of productivity $\phi$ is given by:

$$
x\left(\phi, \lambda_{j k}\right)=p_{j k}^{-\sigma} \frac{1}{\sigma} E_{j k} P_{j k}^{\sigma-1} \chi^{\sigma} \lambda_{j k}^{\sigma} q_{j k}^{\sigma-1}
$$

where $\chi$ is a constant and $\sigma$ is the elasticity of substitution across varieties. By taking logs and rearranging the demand equation, the quality for each firm-product-destinationyear can be estimated.

$$
\tilde{x}_{i j k t}+\sigma \tilde{p}_{i j k t}=\lambda_{j k}+\gamma_{j t}+\delta_{k t}+\phi_{i}+\eta_{i j k t}
$$

Here, tildes represent the natural log of variables. Destination-product fixed effects control for the time-invariant component of product attributes, destination-year and product-year fixed effects control for trends in quality, and firm fixed effects control for overall firm efficiency. Estimated quality can be recovered from the residual variation in equation (27) and the elasticity of substitution: $q_{i j k t}=e^{\left(\eta_{i j k t} /(\sigma-1)\right)}$. I use an estimate of $\sigma=3$, which is the median estimate from Broda et al. (2006) for HS 61 and 62 products.

The results from estimating equation (21) using product quality as a dependent variable are presented in column (3) of Table 10. I find evidence the rules of origin liberalization resulted in upgrades to woven apparel products sent to the EU. The magnitude of the effect is relatively small (roughly $10 \%$ of a standard deviation).

Next, I analyze the effect of the rules of origin revision on quality-adjusted prices. Column (4) of Table 10 presents the results of estimating equation (21) using the log of quality-adjusted price as a dependent variable. Column (5) presents the results of estimating the same regression on a sub-sample containing only incumbent firms. In both cases, quality-adjusted prices fell by roughly 5 percent after the rules of origin 
revision.

Table 10: Prices and product quality

\begin{tabular}{l|cc|c|cc}
\hline \hline & \multicolumn{2}{|c|}{ price } & quality & \multicolumn{2}{c}{ quality adjusted price } \\
& $(1)$ & $(2)$ & $(3)$ & $(4)$ & $(5)$ \\
\hline \hline \multirow{2}{*}{$E U_{j} *{\text { W } \text { oven }_{k} * \text { Post }_{t}}$} & $0.03^{* * *}$ & $0.02^{*}$ & $0.08^{* * *}$ & $-0.04^{* *}$ & $-0.05^{* * *}$ \\
& $(0.011)$ & $(0.012)$ & $(0.03)$ & $(0.018)$ & $(0.017)$ \\
& & & & & \\
Observations & 136,700 & 83,159 & 83,159 & 136,700 & 83,159 \\
R-squared & 0.730 & 0.719 & 0.474 & 0.680 & 0.665 \\
\hline \hline
\end{tabular}

This table displays the results from estimating equation (21) using log price, quality, and $\log$ quality-adjusted price as dependent variables. Columns (2) and (5) restrict the sample to incumbent firms only. All columns contain firm-product, destinationproduct, destination-year, and product-year fixed effects. Errors allow for clustering at the product level in all columns.

\section{Industry Responses}

In this section, I examine how the rules of origin revision influence the composition of the apparel export industry in Bangladesh. I first examine how market shares adjusted across entrants, incumbents, and exiting firms. Then, focusing on incumbent firms, I analyze the response of market shares across incumbent firms of different productivity.

\subsection{Market share reallocation}

In section $5 \mathrm{I}$ document the growth in exports of woven products sold in the EU following the rules of origin liberalization under the EBA. In this section, I analyze how the move from a double-transformation to single-transformation policy influenced the redistribution of market shares across firms in the industry.

Following Khandewal, Schott, and Wei (2013), I decompose export growth into one intensive margin, and two extensive margins. The intensive margin is composed of 
incumbent firms, which are defined as firms that exported the same HS8-level product to the same destination (EU or ROW) before and after the policy change. The extensive margins are composed of entering and exiting firms, which consist of firms that began exporting an HS8-level product to a destination after the policy change and stopped exporting an HS8-level product to a destination after the policy change, respectively.

I then break the two extensive margins down further. Within enterants I define "destination adders" as firms that exported a HS8-level product during the pre- and postpolicy change period, but began exporting the HS8-level product to a new destination after the policy change. Next, I define "product adders" as firms that exported a product to a destination during the pre- and post-policy change period, but began exporting a new HS8-level product to the destination after the policy change. Finally, I define a group of firms called "brand new" firms. These firms began exporting a new HS8-level product to a new destination after the policy change. Exiters are decomposed similarly, expect rather than adding products of destinations, the firms "destination droppers" drop destinations, "product droppers" drop products, and "complete exiters" drop a product-destination pair after the policy change.

For each of these margins $(m)$, I calculate the quantity and value market share across destination-products $(j k)$ in each year. Again, following Khandewal, Schott, and Wei (2013), these market shares are defined by:

$$
\Phi_{m j k t}=\left(\sum_{i \in m} Y_{i j k t} / \sum_{m} \sum_{i} Y_{i j k t}\right)
$$

where, $Y$ refers to either value or quantity of export shipments. I then estimate the following triple-difference regression model for each margin separately: 


$$
\begin{aligned}
\Phi_{j k t}= & \alpha_{0}+\beta_{1}\left(E U_{j} * \text { Woven }_{k} * \text { Post }_{t}\right)+\beta_{2}\left(E U_{j} * \text { Woven }_{k}\right)+\beta_{3}\left(\text { Woven }_{k} * \text { Post }_{t}\right)+ \\
& \beta_{4}\left(E U_{j} * \text { Post }_{t}\right)+\beta_{5}\left(E U_{j} * \text { Woven }_{k}\right)+\beta_{6} E U_{j}+\beta_{7} \text { Woven }_{k}+\beta_{8} \text { Post }_{t}+\epsilon_{j k t}
\end{aligned}
$$

allowing for errors to cluster at the HS8-level. The estimates of $\beta_{1}$ from estimating equation (29) for all nine margins are presented in Table 11, and the full results are presented in Table A4 in the Appendix.

Table 11: Total Market Share Change

\begin{tabular}{ccc}
\hline & Quantity Share & Value Share \\
Incumbent & -0.032 & -0.027 \\
Total Enterants & $0.13^{* * *}$ & $0.12^{* * *}$ \\
Dest Adders & 0.002 & 0.001 \\
Prod Adders & $0.10^{* * *}$ & $0.11^{* * *}$ \\
Brand New & 0.026 & 0.013 \\
Total Exit & $-0.096^{* * *}$ & $-0.094^{* *}$ \\
Prod Dropper & -0.058 & -0.060 \\
Dest Dropper & 0.001 & 0.0003 \\
Complete Exit & $-0.04^{*}$ & $-0.034^{*}$ \\
Net Entry & 0.032 & 0.027 \\
\hline
\end{tabular}

This table displays the results from estimating equation (29) for each margin, shown in equation (28), separately. The full table can be found in the Appendix (Table A4).

Unlike Khandewal, Schott, and Wei (2013), I do not find evidence that the rules of origin liberalization had a statistically significant effect on incumbent market share. That is, the market share of incumbents exporting woven products to EU countries did not change by a statistically significant amount following the policy change. I do find, however, that the market share of enterants who begin selling a woven product to the EU after the policy change increases by 13 percentage points. Within enterants, product adders contribute 77 percent to this increase. This indicates that the main margin of adjustment among enterants comes from firms that were already exporting to the EU and added a woven product after the policy change. 
I find evidence that the market share for exiting firms declines by rough 9.6 percentage points more in the woven-EU market relative to other product-destination markets. Among exiters, the market share of compete exiters is the only marginally significant contributor. This indicates that the firms that stopped selling woven products to the EU after the policy change didn't continue to export knit products to the EU, and didn't continue to export woven products to the ROW. The last row of Table 11 shows the change in net entry, which is not statistically significant.

\subsection{Incumbent market share reallocation}

The evidence provided in Table 11 indicates that incumbent firms did not lose market share to enterants, however market share may have been reallocated within incumbents. In particular, the model predicts that after a rules of origin liberalization market share should be reallocated toward higher productivity incumbent firms. To examine this, I use the number of products a firm exports as a proxy measurement for firm productivity because it is positively correlated with firm productivity in the model. ${ }^{27}$

For each incumbent firm, I determine the average number of products exported per year during the double-transformation period (pre-2011). I then break this measure into quartiles. Next, I follow a similar procedure outlined above, calculating the productdestination level market share for each quartile. I then estimate the triple-difference model in equation (29) using the market share of each quartile as a dependent variable. The results of this exercise are shown in Table 12.

I find evidence that market share of firms in the highest quartile of productivity, measured roughly using the number of products exported, increased by 9 percentage points after the rules of origin liberalization. The lack of reallocation effects at the low end of the productivity distribution is surprising. However, firms at the low end of the productivity distribution may offer products of a lower quality than firms at the high

\footnotetext{
${ }^{27}$ Measuring firm productivity using the number of products firm's export is also done in Bernard, Redding, and Schott (2011).
} 
Table 12: Incumbent Share Change

\begin{tabular}{ccc}
\hline & Quantity Share & Value Share \\
Quartile 1 & 0.02 & 0.01 \\
Quartile 2 & -0.04 & -0.03 \\
Quartile 3 & $-0.07^{*}$ & $-0.07^{*}$ \\
Quartile 4 & $0.09^{* *}$ & $0.09^{* *}$ \\
\hline
\end{tabular}

This table displays the results of estimating equation (29) for each quartile of productivity, measured by the number of products exported in the double-transformation period. The full table is in the appendix (Table A5).

end. Thus, there may be less competition between low and high productivity firms and more competition between firms at the high end of the productivity distribution.

\section{Conclusion}

In this paper, I show how restrictive rules of origin act as barriers to market access for firms in LDCs. Exploiting technical differences in the production of different types of textiles, and a revision to the rules of origin governing preferential access to the EU market for apparel producers in LDCs, I find rules of origin not only restrict firm entry into the export market, but also reduce the range of products they sell, and the average export revenue they earn per product.

The results indicate that rules of origin can have a sizable effect on the flow of trade. In particular, I show that in the context of a labor-abundant country (like Bangladesh) firms that must rely on capital-intensive inputs are put at a disadvantage under strict rules of origin. Given the small amount of textile production in Bangladesh, the potential losses from this policy change for Bangladeshi woven textiles producers is likely small, although data limitations restrict me from directly analyzing this. From a policy perspective, the results shed light on an under-studied trade barrier that is typically 
embedded within preferential trade agreements. Policy makers attempting to improve conditions in developing countries through trade policy may be able to affect outcomes without lowering traditional barriers like tariffs or quotas by adjusting the rules of origin.

While this study focuses on the apparel industry, the theoretical model offers insight into how firms in other industries may respond to rules of origin. For example, the discussion surrounding the potential transition from the North American Free Trade Agreement (NAFTA) to the US-Mexico-Canada (USMCA) agreement has highlighted the restrictions on the rules of origin for automobile manufacturing. ${ }^{28}$ U.S. policy makers hope that requiring more within-region content in automobiles will result in car manufactures using more American made components. The model in this paper shows that firms may simply choose to source inputs from lower cost suppliers and face higher tariffs than satisfy restrictive rules of origin. Future work should formally analyze this in the context of renegotiated trade agreements.

Lastly, in this paper I offer additional context to debates regarding the trade relationships between high- and low-income countries. Flentø and Ponte (2017) note that while there is a general consensus in trade and development policy circles that trade negotiations between developed and LDCs should aim to reduce trade barriers for exporters in LDCs there is less consensus on how this should be achieved. The results of this study show that revising rules of origin is a viable option within this debate.

${ }^{28}$ See: https://piie.com/newsroom/short-videos/toughening-naftas-rules-origin-could-backfire 
References

\section{References}

[1] Agarwal, Rajshree, and Michael Gort. "Firm and product life cycles and firm survival." American Economic Review 92.2 (2002): 184-190.

[2] Ahsan, Reshad, and Kazi Iqbal. "How Does Violence Affect Exporters? Evidence from Political Strikes in Bangladesh." (2017)

[3] Amiti, Mary, and Jozef Konings. "Trade liberalization, intermediate inputs, and productivity: Evidence from Indonesia." American Economic Review 97.5 (2007): 1611-1638.

[4] Amiti, Mary, and Amit K. Khandelwal. "Import competition and quality upgrading." Review of Economics and Statistics 95.2 (2013): 476-490.

[5] Anson, José, et al. "Rules of origin in North-South preferential trading arrangements with an application to NAFTA." Review of International Economics 13.3 (2005): 501-517.

[6] Augier, P., M. Gasiorek and C. Lai-Tong (2004). "Rules of origin and the EU-Med partnership: the case of textiles", World Economy, 27(9), 1449-73.

[7] Augier, Patricia, Michael Gasiorek, and Charles Lai Tong. "The impact of rules of origin on trade flows." Economic Policy 20.43 (2005): 568-624.

[8] Baggs, Jen. "Firm survival and exit in response to trade liberalization." Canadian Journal of Economics/Revue canadienne d'économique 38.4 (2005): 1364-1383.

[9] Bakht, Zaid, et al. "Competitiveness of a labor-intensive industry in a least developed country: A case of the knitwear industry in Bangladesh." mimeographed, Chiba, Japan: Institute of Developing Economies (2006).

[10] Barber, Catherine, Balachandiran Gowthaman, and Jonathan Rose. "Stitched Up: How rich country protectionism in textiles and clothing trade prevents poverty alleviation." (2004).

[11] Bernard, Andrew B., Stephen J. Redding, and Peter K. Schott. "Multiproduct firms and trade liberalization." The Quarterly Journal of Economics 126.3 (2011): 1271-1318.

[12] Bas, Maria, and Antoine Berthou. "Does input-trade liberalization affect firms' foreign technology choice?." The World Bank Economic Review 31.2 (2017): 351384 . 
[13] Bas, Maria, and Vanessa Strauss-Kahn. "Input-trade liberalization, export prices and quality upgrading." Journal of International Economics 95.2 (2015): 250-262.

[14] Bas, Maria, and Vanessa Strauss-Kahn. "Does importing more inputs raise exports? Firm-level evidence from France." Review of World Economics 150.2 (2014): 241-275.

[15] Besley, Timothy, and Anne Case. "Unnatural experiments? Estimating the incidence of endogenous policies." The Economic Journal 110.467 (2000): 672-694.

[16] Brenton, Paul. "Enhancing trade preferences for LDCs: reducing the restrictiveness of rules of origin." 00 Trade, Doha, and Development (2006): 281.

[17] Broda, Christian, Joshua Greeneld and David Weinstein (2006). "FromGroundnuts to Globalization: A Structural Estimate of Trade and Growth",NBER Working Paper 12512 .

[18] Brown, Chad, and Meredith A. Crowley. "Emerging economies, trade policy, and macroeconomic shocks". Journal of Development Economics, Volume 111 (2014): $261-273$

[19] Bussolo, Maurizio \& Vargas Da Cruz, Marcio Jose, 2015. "Does input tariff reduction impact firms' exports in the presence of import tariff exemption regimes ?," Policy Research Working Paper Series 7231, The World Bank.

[20] Bustos, Paula. "Trade liberalization, exports, and technology upgrading: Evidence on the impact of MERCOSUR on Argentinian firms." American economic review 101.1 (2011): 304-40.

[21] Cadot, Olivier, Antoni Estevadeordal, and Akiko Suwa-Eisenmann. "Rules of origin as export subsidies." (2005).

[22] Cadot, Olivier, et al. "Do Rules of Origin Constrain Export Growth? Firm-Level Evidence from Colombia". Inter-American Development Bank, 2014.

[23] Carrère, Céline, Jaime De Melo, and Bolormaa Tumurchudur. "Disentangling market access effects of preferential trading arrangements with an application for ASEAN members under an ASEAN-EU FTA." World Economy 33.1 (2010): 42-59.

[24] Cheong, Juyoung, Do Won Kwak, and Haishan Yuan. "Trade to aid: EU's temporary tariff waivers for flood-hit Pakistan." Journal of Development Economics 125 (2017): 70-88.

[25] Cherkashin, Ivan, et al. "Firm heterogeneity and costly trade: A new estimation strategy and policy experiments". The World Bank, 2015.

[26] Ciani, Emanuele, and Paul Fisher. "Dif-in-dif estimators of multiplicative treatment effects." Journal of Econometric Methods (2013). 
[27] Clotfelter, Charles, et al. "Would higher salaries keep teachers in high-poverty schools? Evidence from a policy intervention in North Carolina." Journal of Public Economics 92.5-6 (2008): 1352-1370.

[28] Conconi, Paola, et al. "From final goods to inputs: the protectionist effect of rules of origin." American Economic Review 108.8 (2018): 2335-65.

[29] Coyle, John. "Rules of origin as instruments of foreign economic policy: an analysis of the integrated sourcing initiative in the US-Singapore free trade agreement." Yale J. Int'l L. 29 (2004): 545.

[30] Curran, Louise, and Khalid Nadvi. "Shifting trade preferences and value chain impacts in the Bangladesh textiles and garment industry." Cambridge Journal of Regions, Economy and Society 8.3 (2015): 459-474.

[31] Demidova, Svetlana, Hiau Looi Kee, and Kala Krishna. "Do trade policy differences induce sorting? Theory and evidence from Bangladeshi apparel exporters." Journal of International Economics 87.2 (2012): 247-261.

[32] Edwards, Sebastian. "Openness, trade liberalization, and growth in developing countries." Journal of economic Literature 31.3 (1993): 1358-1393.

[33] Estevadeordal, Antoni (2000), "Negotiating Preferential Market Access: The Case of the North American Free Trade Agreement", Journal of World Trade 34, 141-2000.

[34] Fan, Haichao, Yao Amber Li, and Stephen R. Yeaple. "Trade liberalization, quality, and export prices." Review of Economics and Statistics 97.5 (2015): 1033-1051.

[35] Flentø, Daniel, and Stefano Ponte. "Least-developed countries in a world of global value chains: are WTO trade negotiations helping?." World Development 94 (2017): 366-374.

[36] Frazer, Garth, and Johannes Van Biesebroeck. "Trade growth under the african growth and opportunity act." The Review of Economics and Statistics 92.1 (2010): 128-144.

[37] Frederick, Stacey, and Cornelia Staritz. "Developments in the global apparel industry after the MFA phaseout." 2012. 41-85.

[38] Garetto, Stefania. "Input sourcing and multinational production." American Economic Journal: Macroeconomics 5.2 (2013): 118-51.

[39] Gereffi, Gary. "International trade and industrial upgrading in the apparel commodity chain." Journal of international economics 48.1 (1999): 37-70.

[40] Gil-Pareja, Salvador, Rafael Llorca-Vivero, and José Antonio Martínez-Serrano. "Do nonreciprocal preferential trade agreements increase beneficiaries' exports?." Journal of development economics 107 (2014): 291-304. 
[41] Goldberg, Pinelopi Koujianou, et al. "Imported intermediate inputs and domestic product growth: Evidence from India." The Quarterly journal of economics 125.4 (2010): 1727-1767.

[42] Grossman, Gene M., and Elhanan Helpman. "Endogenous innovation in the theory of growth." Journal of Economic Perspectives 8.1 (1994): 23-44.

[43] Halpern, László, Miklós Koren, and Adam Szeidl. "Imported inputs and productivity." American Economic Review 105.12 (2015): 3660-3703.

[44] Harris, Jeremy T. "Rules of origin for development: from GSP to global free trade". No. IDB-WP-135. IDB Working Paper Series, 2009.

[45] Hakobyan, Shushanik. "Accounting for underutilization of trade preference programs: The US generalized system of preferences." Canadian Journal of Economics/Revue canadienne d'économique 48.2 (2015): 408-436.

[46] Hayakawa, Kazunobu. "Impact of diagonal cumulation rule on FTA utilization: Evidence from bilateral and multilateral FTAs between Japan and Thailand." Journal of the Japanese and International Economies 32 (2014): 1-16.

[47] Heath, Rachel. "Why do Firms Hire Using Referrals? Evidence from Bangladeshi Garment Factories" Journal of Political Economy. (2018)

[48] Herin, Jan (1986), "Rules of Origin and Differences Between Tariff Levels in EFTA and in the EC", EFTA Occasional Paper 13

[49] Hummels, David, Jun Ishii, and Kei-Mu Yi. "The nature and growth of vertical specialization in world trade." Journal of international Economics 54.1 (2001): 7596.

[50] Liu, Xuepeng. "Trade Agreements and Economic Growth." Southern Economic Journal 82.4 (2016): 1374-1401.

[51] Lopez-Acevedo, Gladys; Robertson, Raymond. 2016. Stitches to Riches? : Apparel Employment, Trade, and Economic Development in South Asia. Directions in Development-Poverty;. Washington, DC: World Bank. (c) World Bank. https://openknowledge.worldbank.org/handle/10986/23961 License: CC BY 3.0 IGO.

[52] Kabir, Mahfuz; Singh, Surendar; Ferrantino, Michael Joseph. 2019. The TextileClothing Value Chain in India and Bangladesh : How Appropriate Policies Can Promote (or Inhibit) Trade and Investment (English). Policy Research working paper; no. WPS 8731. Washington, D.C. : World Bank Group.

[53] Kasahara, Hiroyuki, and Joel Rodrigue. "Does the use of imported intermediates increase productivity? Plant-level evidence." Journal of development economics 87.1 (2008): 106-118. 
[54] Kee, Hiau Looi. "Foreign ownership and firm productivity in Bangladesh garment sector." Development Research Group-Trade, The World Bank, Washington DC, USA (2005).

[55] Kee, Hiau Looi, and Kala Krishna. "Firm-level heterogeneous productivity and demand shocks: Evidence from Bangladesh." American Economic Review 98.2 (2008): $457-62$.

[56] Keho, Yaya. "The impact of trade openness on economic growth: The case of Cote d'Ivoire." Cogent Economics \& Finance 5.1 (2017): 1332820.

[57] Kugler, Maurice, and Eric Verhoogen. "Prices, plant size, and product quality." The Review of Economic Studies 79.1 (2011): 307-339.

[58] Masum, Md. "The Bangladesh Textile-Clothing Industry: A Demand-Supply Review." Social Systems Research 33 (2016): 109-139.

[59] Melitz, Marc. "The impact of trade on intra industry reallocations and aggregate industry productivity." Econometrica 71.6 (2003): 1695-1725.

[60] Miroudot, S., R. Lanz and A. Ragoussis (2009), "Trade in Intermediate Goods and Services", OECD Trade Policy Papers, No. 93, OECD Publishing, Paris, https://doi.org/10.1787/5kmlcxtdlk8r-en.

[61] Özden, Çaglar, and Eric Reinhardt. "The perversity of preferences: GSP and developing country trade policies, 1976-2000." Journal of Development Economics 78.1 (2005): 1-21.

[62] Rahman, M. (2011). Trade Benefits for Least Developed Countries: The Bangladesh Case. Market Access Initiatives, Limitations and Policy Recommendations. Dhaka, Bangladesh: Centre for Policy Dialogue

[63] Schröder, Philipp JH, and Allan Sørensen. "Firm exit, technological progress and trade." European Economic Review (2011).

[64] Sekkel, Julia. "Summary of major trade preference programs." V Center for Global Develop) ment (2009).

[65] Shang, Shengwu, Erik Nesson, and Maoyong Fan. "Interaction Terms in Poisson and Log Linear Regression Models." Bulletin of Economic Research 70.1 (2018): E89-E96.

[66] Topalova, Petia, and Amit Khandelwal. "Trade liberalization and firm productivity: The case of India." Review of economics and statistics 93.3 (2011): 995-1009.

[67] World Bank. 1999. Bangladesh - Trade liberalization : its pace and impacts (English). Washington, DC: World Bank. http://documents.worldbank.org/curated/en/231361468013243681/BangladeshTrade-liberalization-its-pace-and-impacts 
[68] Yi, Kei-Mu. "Can vertical specialization explain the growth of world trade?." Journal of political Economy 111.1 (2003): 52-102. 


\section{Appendix}

\subsection{Proof of Proposition 1}

I assume product attributes have a Pareto distribution, $Z(\lambda)=1-\left(\frac{\lambda}{\lambda_{\min }}\right)^{-k}$. With the minimum level of product attributes necessary to cover the fixed costs given by $\lambda_{j k}^{*}\left(\phi^{*}\right)$, the Pareto distribution takes the form: $Z\left(\lambda_{j k}\right)=1-\left(\frac{\lambda_{j k}}{\lambda_{j k}^{M F N}\left(\phi^{*}\right)}\right)^{-k}$. Here, I retain the usual assumption that $k>\sigma-1$ required for trade flows to be finite. Proof of Proposition 1: Equation (19) can be rewritten as:

$$
\begin{array}{r}
\sigma f_{j k} \int_{\lambda^{M F N}\left(\phi^{*}\right)}^{\lambda^{P T A}\left(\phi^{*}\right)}\left[\left(\frac{\lambda_{j k}(\phi)}{\lambda^{M F N}\left(\phi^{*}\right)}\right)^{\sigma-1}-1\right]\left(\frac{\partial\left(1-\left(\frac{\lambda_{j k}(\phi)}{\lambda^{M F N}\left(\phi^{*}\right)}\right)^{-k}\right)}{\partial \lambda}\right) \partial \lambda+ \\
\sigma f_{j k} \int_{\lambda^{P T A}\left(\phi^{*}\right)}^{\infty}\left[\left(\frac{\lambda_{j k}(\phi)}{\lambda^{P T A}\left(\phi^{*}\right)}\right)^{\sigma-1}-1\right]\left(\frac{\partial\left(1-\left(\frac{\lambda_{j k}(\phi)}{\lambda^{M F N}\left(\phi^{*}\right)}\right)^{-k}\right)}{\partial \lambda}\right) \partial \lambda-F_{j}
\end{array}
$$

Working in parts, the first half of the equation results in:

$$
k \sigma f_{j k} \int_{\lambda^{M F N}\left(\phi^{*}\right)}^{\theta \lambda^{M F N}\left(\phi^{*}\right)}\left[\left(\frac{\lambda_{j k}(\phi)}{\lambda^{M F N}\left(\phi^{*}\right)}\right)^{\sigma-1}-1\right]\left(\frac{\lambda_{j k}(\phi)}{\lambda^{M F N}\left(\phi^{*}\right)}\right)^{-k-1} \partial \lambda
$$

Where, $\lambda^{P T A}\left(\phi^{*}\right)=\theta \lambda^{M F N}\left(\phi^{*}\right)$ from equation (18) in the text. Equation (A2) can be rearranged and integrated into:

$$
\sigma f_{j k}\left[\frac{\left(\frac{\lambda_{j k}(\phi)}{\lambda^{M F N}\left(\phi^{*}\right)}\right)^{\sigma-k-1}}{\sigma-k-1}+\frac{\left(\frac{\lambda_{j k}(\phi)}{\lambda^{M F N}\left(\phi^{*}\right)}\right)^{-k}}{k}\right]_{\lambda^{M F N}\left(\phi^{*}\right)}^{\theta \lambda^{M F N}\left(\phi^{*}\right)}
$$

When evaluated at the limits, this becomes:

$$
\sigma f_{j k}\left[\frac{\theta^{\sigma-k-1}}{\sigma-k-1}+\frac{\theta^{-k}}{k}\right]+\sigma f_{j k}\left[\frac{1}{\sigma-k-1}+\frac{1}{k}\right]
$$

Defining, $\sigma\left[\frac{1}{\sigma-k-1}+\frac{1}{k}\right]=C$ to save notation, equation (A6) can be expressed as:

$$
\sigma f_{j k}\left[\frac{\theta^{\sigma-k-1}}{\sigma-k-1}+\frac{\theta^{-k}}{k}\right]+f_{j k} C
$$


Next, working from the second half of equation (A1), produces:

$$
\sigma\left(f_{j k}+d_{j}\right)\left[\frac{\left(\frac{\lambda_{j k}(\phi)}{\theta \lambda^{M F N}\left(\phi^{*}\right)}\right)^{\sigma-k-1}}{\sigma-k-1}+\frac{\left(\frac{\lambda_{j k}(\phi)}{\theta \lambda^{M F N}\left(\phi^{*}\right)}\right)^{-k}}{k}\right]_{\theta \lambda^{M F N}\left(\phi^{*}\right)}^{\infty}
$$

Where the identify in equation (18) has been used again to replace $\lambda^{P T A}(\phi)$. When (A6) is evaluated at it's limits, the resulting expression is:

$$
-\left(f_{j k}+d_{j}\right) C
$$

Combining equations (A4) and (A6) results in the expression:

$$
\sigma f_{j k}\left[\frac{\theta^{\sigma-k-1}}{\sigma-k-1}+\frac{\theta^{-k}}{k}\right]-d_{j} C
$$

From equation (18) in the text, $\theta$ is an increasing function of $\bar{p}_{x, k}$. A relaxation of the rules of origin reduces $\bar{p}_{x, k}$. Thus, to see how $\Pi\left(\phi^{*}\right)$ responds to a revision of the rules of origin, it is sufficient to show that the derivative of (A8) with respect to $\theta$ is positive. Differentiating (A8) with respect to $\theta$ results in:

$$
\frac{\partial \Pi}{\partial \theta}=\sigma f_{j k}\left[\theta^{\sigma-k-2}-\theta^{-k-1}\right]
$$

The expression in the brackets is greater than zero if and only if:

$$
\frac{1}{\theta^{k+2-\sigma}}>\frac{1}{\theta^{k+1}} \Longleftrightarrow \theta^{k+1}>\theta^{k+2-\sigma}
$$

Because $\sigma>1$, this is true. An increase in $\Theta$ results in an increase in $\Pi\left(\phi^{*}\right)$, and because expected profits are strictly increasing in firm ability, this results in an increase in $\phi^{*}$. Thus, because $\frac{\partial \Theta}{\partial \bar{p}_{x, k}}>0$, liberalizing the rules of origin (i.e. reducing $\bar{p}_{x, k}$ ) reduces the zero-profit cutoff for firm ability. Intuitively, a relaxation of the rules of origin increases the expected profits from exporting to country $j$ for all firms by reducing the 
prices they charge, and increasing the probability of drawing desirable enough product attributes in market $j$. Thus, lower ability firms are able to enter the export market.

\subsection{Higher frequency data}

I estimate the main regression equations in the text using higher frequency data. I first show the triple difference effect graphically in Figure A1, which uses monthly, rather than annual data. On the y-axis I plot the difference between (EU Woven - ROW Woven) and (EU Knit - ROW Knit), and on the x-axis is the time. There does not appear to be anticipation of the rules of origin revision by Bangladeshi exporters. If there were, Figure A1 who show an increase in triple-difference effect in the months leading up to the rules of origin revision. The dashed line represents when the rules of origin were revised. Next, I estimate equations (22)-(24) in the text with quarterly data. The results are presented in Table A1. The results are very similar to the results in the text.

Table A1: Quarterly Data

\begin{tabular}{|c|c|c|c|}
\hline & $\begin{array}{c}(1) \\
\text { Export Revenue }\end{array}$ & $\begin{array}{c}(2) \\
\text { Number of products per firm }\end{array}$ & $\begin{array}{c}(3) \\
\text { Number of firms per product }\end{array}$ \\
\hline Woven $_{k}$ & & $\begin{array}{l}0.23^{* *} \\
(0.103)\end{array}$ & \\
\hline$E U_{j} *$ Woven $_{k}$ & & $\begin{array}{c}0.00 \\
(0.043)\end{array}$ & $\begin{array}{l}-0.01 \\
(0.056)\end{array}$ \\
\hline$E U_{j} *$ Post $_{t}$ & & $\begin{array}{c}-0.24^{* * *} \\
(0.024)\end{array}$ & $\begin{array}{c}-0.28^{* * *} \\
(0.021)\end{array}$ \\
\hline$E U_{j} *$ Woven $_{k}$ & & $\begin{array}{c}-0.79^{* * *} \\
(0.094)\end{array}$ & \\
\hline EU $_{j} *$ Woven $_{k} *$ Post $_{t}$ & $\begin{array}{c}0.18^{* * *} \\
(0.046)\end{array}$ & $\begin{array}{c}0.17 * * * \\
(0.037)\end{array}$ & $\begin{array}{l}0.18^{* *} \\
(0.039)\end{array}$ \\
\hline $\begin{array}{l}\text { Observations } \\
\text { R-squared }\end{array}$ & $\begin{array}{c}189,724 \\
0.500\end{array}$ & 130,918 & 10,153 \\
\hline $\begin{array}{l}\text { This table displays the re } \\
\text { annual data. The first colu } \\
5 \text {. It includes firm-product } \\
\text { year-quarter. The second c } \\
6 \text {. It includes firm-destina } \\
\text { comparable to column (3) }\end{array}$ & $\begin{array}{l}\text { lts of estimating th } \\
\mathrm{n} \text { displays the resul } \\
\text { destination-product } \\
\text { umn displays the wi } \\
\text { on, and time fixed } \\
\text { Table } 7 \text {. It include }\end{array}$ & $\begin{array}{l}\text { main regression models in the } \\
\text { s for the intensive margin, and is } \\
\text { product-time, destination-time } \mathrm{f} \\
\text { hin-firm extensive margin, and is } \\
\text { ffects. Column } 3 \text { displays the ac } \\
\text { destination-product, and time fix }\end{array}$ & $\begin{array}{l}\text { aper using quarterly, rather than } \\
\text { comparable to column (3) in Table } \\
\text { xed effects. Here time, refers to a } \\
\text { comparable to column (3) of Table } \\
\text { ross-firm extensive margin, and is } \\
\text { ed effects. }\end{array}$ \\
\hline
\end{tabular}




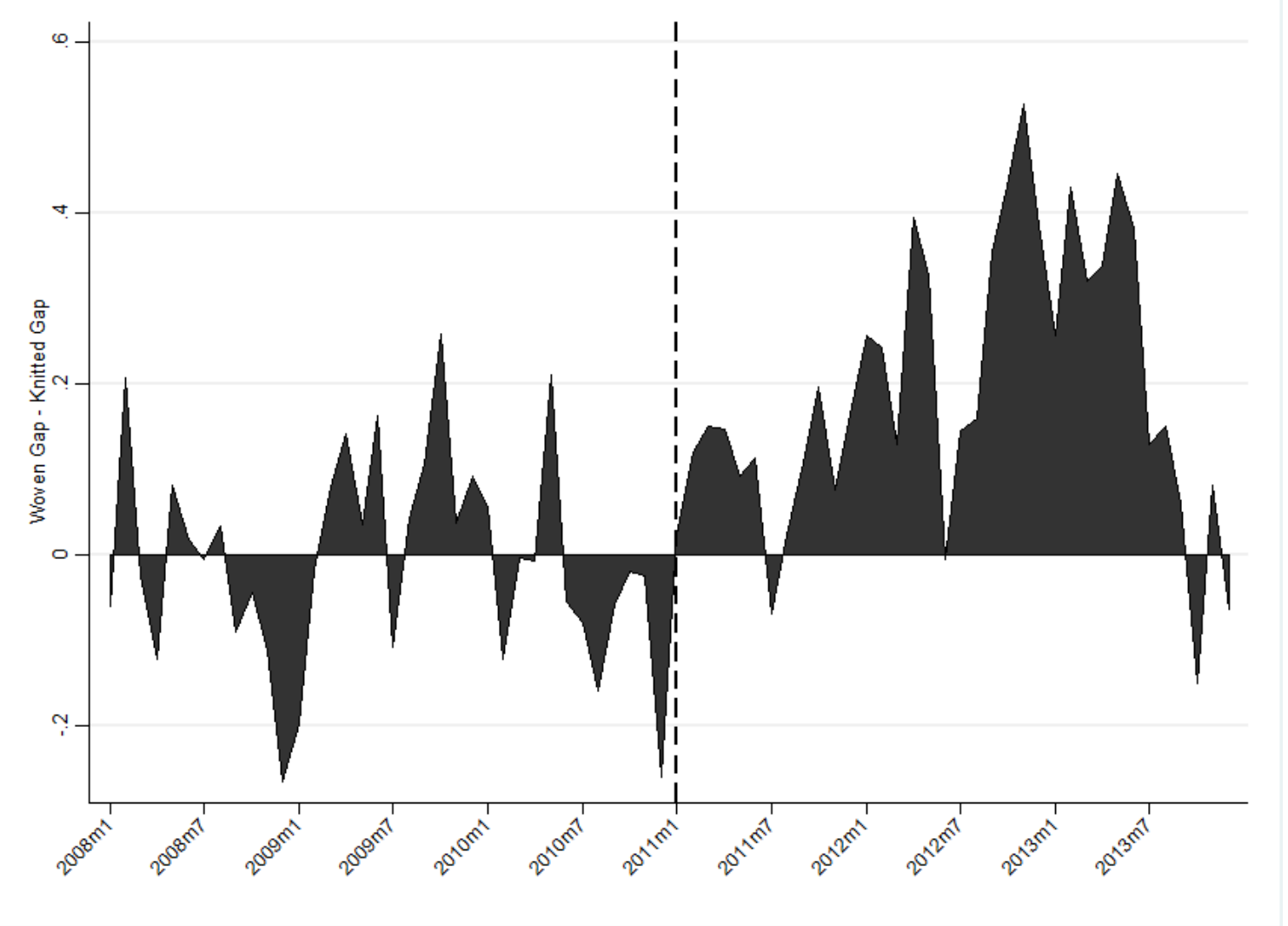

Figure A1: This figure displays the difference between woven exports sent to the EU and woven exports sent to the ROW, and knit exports sent to the Eu and knit exports sent to the ROW. This is the triple-difference estimate. The data is at the monthly level. The dashed vertical line represents when the single-transformation policy went into effect.

\subsection{Effect on Imports}

To explore how imports of textiles responded to the revision of the rules of origin, I collect data from COMTRADE on woven and knitted textiles imported into Bangladesh over the relevant time period (2008-2013). Figure A2 displays the top ten sources for textiles used in the production of apparel in Bangladesh in the pre-2011 years. I do not have data on firm-level imports of textiles. I then use the COMTRADE data to estimate the following difference-in-difference model: 


$$
\log \left(\text { import }_{j k t}\right)=\beta_{1}\left(\text { Woven }_{k} * \text { Post }_{t}\right)+\gamma_{j t}+\alpha_{k}+\epsilon_{j k t}
$$

where, import $_{j k t}$ is the value of imported textile product $k$ from origin $j$ in year $t$. I include origin-year and product fixed effects. I allow the error term to cluster at the product level. Products refer to HS 6 level codes.

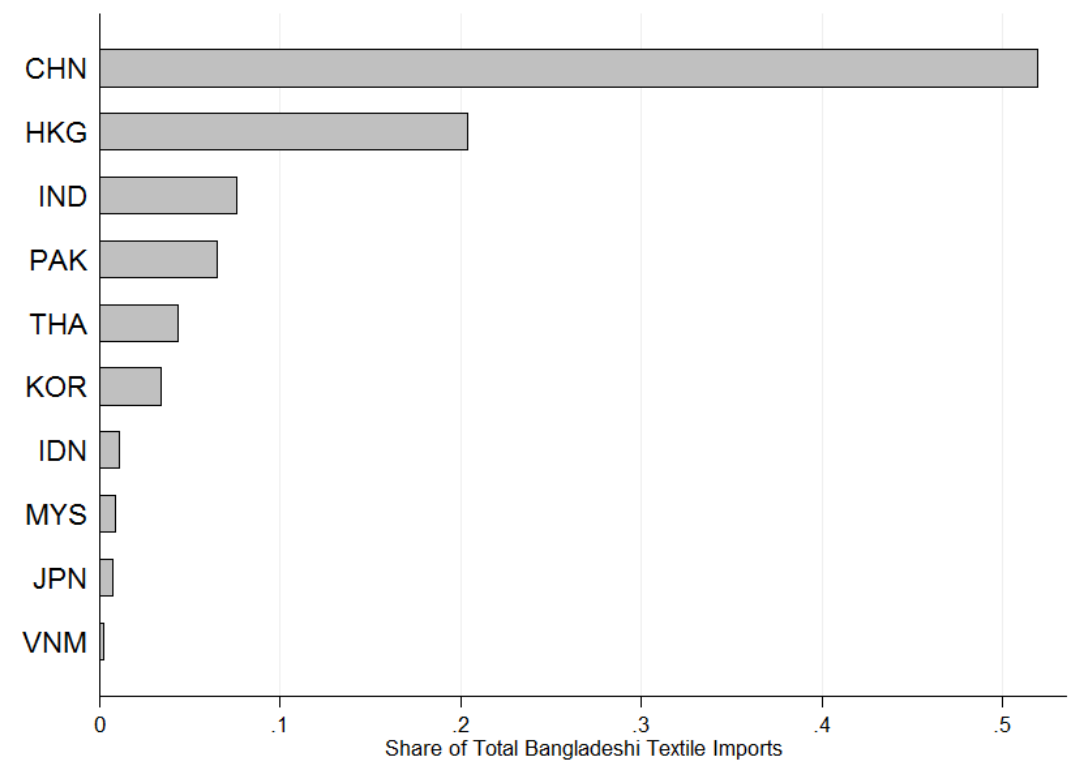

Figure A2: This figure displays the import share of the top ten textile sources for Bangladesh during the pre-2011 years.

The results of estimating equation (A1) are presented in Table A2. The first column displays the results when estimated on the full sample. The second column displays the results when estimated using only the top 10 origins, as shown in Figure A2, in the main text. The third column shows the results using the full sample and interacting the Woven $_{k} *$ Post $_{t}$ variable with an indicator that takes the value of one if origin $j$ is an LDC country. The revision of the double transformation policy did result in a statistically significant decline in the value of imported textiles from LDC countries. The double-transformation policy allowed for imports of textiles from other LDC countries. 
Bangladeshi textiles imports appear to substitute away from LDC countries after the rules of origin revision.

Table A2: Imports of textiles

\begin{tabular}{|c|c|c|c|}
\hline & (1) & $\begin{array}{c}(2) \\
\text { Only Top } 10 \\
\end{array}$ & $(3)$ \\
\hline Woven $_{k} *$ Post $_{t}$ & $\begin{array}{c}-0.04 \\
(0.206)\end{array}$ & $\begin{array}{c}0.14 \\
(0.232)\end{array}$ & $\begin{array}{c}-0.02 \\
(0.203)\end{array}$ \\
\hline Woven $_{k} *$ Post $_{t} * I(L D C=1)$ & & & $\begin{array}{c}-2.05^{* * *} \\
(0.768)\end{array}$ \\
\hline Observations & 10,499 & 6,116 & 10,499 \\
\hline R-squared & 0.575 & 0.602 & 0.575 \\
\hline Fixed Effects & Commodity, Origin-Year & Commodity, Origin-Year & Commodity, Origin-Year \\
\hline
\end{tabular}

The lack of statistical significance in column 2 of table A2 may be due to heterogeneity across origin country. To further investigate the effect of the rules of origin revision on textile imports, I estimate equation (A1) separately for each of the top 10 trading partners. Table A3 displays the results. I find that imports of textiles from China increased after the policy change. China's woven textile production industry is highly developed, and can offer textiles at a low cost. Bangladeshi importers also reduced imports of textiles from Vietnam, which was the 10th largest supplier of textiles prior to the rules of origin revision. The change in imports from other sources is less precisely estimated. The results are similar if log-quantity is used as a dependent variable. 
Table A3: Imports of textiles-Top 10 Partners

\begin{tabular}{|c|c|c|}
\hline Origin & $\beta_{1}$ & Number of Observations \\
\hline China & $\begin{array}{l}0.52^{* *} \\
(0.25)\end{array}$ & 1063 \\
\hline Hong Kong & $\begin{array}{c}0.41 \\
(0.36)\end{array}$ & 881 \\
\hline India & $\begin{array}{l}-0.09 \\
(0.31)\end{array}$ & 776 \\
\hline Pakistan & $\begin{array}{c}0.52 \\
(0.76)\end{array}$ & 538 \\
\hline Thailand & $\begin{array}{l}-0.45 \\
(0.55)\end{array}$ & 612 \\
\hline South Korea & $\begin{array}{l}-0.41 \\
(0.63)\end{array}$ & 677 \\
\hline Indonesia & $\begin{array}{c}0.52 \\
(0.51)\end{array}$ & 418 \\
\hline Malaysia & $\begin{array}{l}-0.93 \\
(0.65)\end{array}$ & 311 \\
\hline Japan & $\begin{array}{c}0.68 \\
(0.47)\end{array}$ & 296 \\
\hline Vietnam & $\begin{array}{c}-2.58^{* * *} \\
(0.79)\end{array}$ & 281 \\
\hline
\end{tabular}

This table displays the results of estimating the regression model laid out in equation A1. The regression is estimated separately for each of the top 10 suppliers of Bangladeshi textiles. 
Table A4

\begin{tabular}{|c|c|c|c|c|c|c|c|c|c|c|}
\hline & $\begin{array}{c}(1) \\
\text { Total Enter }\end{array}$ & $\begin{array}{c}(2) \\
\text { Dest. Adders }\end{array}$ & $\begin{array}{c}(3) \\
\text { Prod. Adders }\end{array}$ & $\begin{array}{c}\text { (4) } \\
\text { Brand New }\end{array}$ & $\begin{array}{c}(5) \\
\text { Total Exit }\end{array}$ & $\begin{array}{c}(6) \\
\text { Prod Droppers }\end{array}$ & $\begin{array}{c}(7) \\
\text { Dest Droppers }\end{array}$ & $\begin{array}{c}(8) \\
\text { Complete Exit }\end{array}$ & $\begin{array}{c}\text { (9) } \\
\text { Incumbent }\end{array}$ & $\begin{array}{c}(10) \\
\text { Net Entry }\end{array}$ \\
\hline \multicolumn{11}{|l|}{ Quantity Share } \\
\hline \multirow[t]{2}{*}{ t } & $0.13^{* * *}$ & 0.00 & $0.10^{* * *}$ & 0.03 & $-0.10^{* * *}$ & -0.06 & 0.00 & $-0.04^{*}$ & 0.03 & -0.03 \\
\hline & $(0.033)$ & $(0.003)$ & $(0.033)$ & $(0.024)$ & $(0.035)$ & $(0.037)$ & $(0.002)$ & $(0.021)$ & $(0.032)$ & $(0.032)$ \\
\hline \multirow[t]{2}{*}{ Constant } & $0.30^{* * *}$ & $0.00^{*}$ & $0.19^{* * *}$ & $0.11^{* * *}$ & $0.32^{* * *}$ & $0.27^{* * *}$ & $0.00^{* * *}$ & $0.05^{* * *}$ & $0.62^{* * *}$ & $0.38^{* * *}$ \\
\hline & $(0.009)$ & $(0.000)$ & $(0.009)$ & $(0.005)$ & $(0.010)$ & $(0.010)$ & $(0.000)$ & $(0.005)$ & $(0.016)$ & $(0.016)$ \\
\hline Observations & 2,577 & 2,577 & 2,577 & 2,577 & 2,577 & 2,577 & 2,577 & 2,577 & 2,577 & 2,577 \\
\hline R-squared & 0.663 & 0.005 & 0.466 & 0.241 & 0.603 & 0.525 & 0.004 & 0.114 & 0.014 & 0.014 \\
\hline \multirow[t]{2}{*}{$\mathrm{t}$} & $0.12^{* * *}$ & 0.00 & $0.11^{* * *}$ & 0.01 & $-0.09^{* * *}$ & -0.06 & 0.00 & $-0.03^{*}$ & 0.03 & -0.03 \\
\hline & $(0.032)$ & $(0.003)$ & $(0.033)$ & $(0.022)$ & $(0.034)$ & $(0.036)$ & $(0.002)$ & $(0.020)$ & $(0.032)$ & $(0.032)$ \\
\hline \multirow[t]{2}{*}{ Constant } & $0.29^{* * *}$ & $0.00^{* *}$ & $0.19^{* * *}$ & $0.10^{* * *}$ & $0.31^{* * *}$ & $0.27^{* * *}$ & $0.00^{* * *}$ & $0.05^{* * *}$ & $0.61^{* * *}$ & $0.39^{* * *}$ \\
\hline & (0.009) & $(0.000)$ & $(0.009)$ & $(0.005)$ & $(0.010)$ & $(0.010)$ & $(0.000)$ & $(0.004)$ & $(0.017)$ & $(0.017)$ \\
\hline Observations & 2,577 & 2,577 & 2,577 & 2,577 & 2,577 & 2,577 & 2,577 & 2,577 & 2,577 & 2,577 \\
\hline R-squared & 0.644 & 0.005 & 0.455 & 0.231 & 0.582 & 0.511 & 0.005 & 0.107 & 0.013 & 0.013 \\
\hline
\end{tabular}

This table displays the results of estimating the regression model laid out in equation (29). 
Table A5: Incumbent Share Change

\begin{tabular}{|c|c|c|c|c|}
\hline & $\begin{array}{c}\text { (1) } \\
\text { Quartile } 1\end{array}$ & $\begin{array}{c}(2) \\
\text { Quartile } 2\end{array}$ & $\begin{array}{c}(3) \\
\text { Quartile } 3\end{array}$ & $\begin{array}{c}(4) \\
\text { Quartile } 4\end{array}$ \\
\hline \multicolumn{5}{|l|}{ Quantity Share } \\
\hline EU $_{j} *$ Woven $_{k} *$ Post $_{t}$ & $\begin{array}{c}0.02 \\
(0.032)\end{array}$ & $\begin{array}{c}-0.04 \\
(0.033)\end{array}$ & $\begin{array}{l}-0.07^{*} \\
(0.039)\end{array}$ & $\begin{array}{l}0.09^{* *} \\
(0.041)\end{array}$ \\
\hline Constant & $\begin{array}{c}0.15^{* * *} \\
(0.014)\end{array}$ & $\begin{array}{c}0.18^{* * *} \\
(0.014)\end{array}$ & $\begin{array}{c}0.27^{* * *} \\
(0.015)\end{array}$ & $\begin{array}{c}0.40 * * * \\
(0.019)\end{array}$ \\
\hline Observations & 1,939 & 1,939 & 1,939 & 1,939 \\
\hline R-squared & 0.036 & 0.013 & 0.003 & 0.033 \\
\hline Value Share & & & & \\
\hline$E_{j} *$ Woven $_{k} *$ Post $_{t}$ & $\begin{array}{c}0.01 \\
(0.029)\end{array}$ & $\begin{array}{c}-0.03 \\
(0.032)\end{array}$ & $\begin{array}{l}-0.07^{*} \\
(0.039)\end{array}$ & $\begin{array}{c}0.09^{* *} \\
(0.039)\end{array}$ \\
\hline Constant & $\begin{array}{c}0.14^{* * *} \\
(0.014)\end{array}$ & $\begin{array}{c}0.18^{* * *} \\
(0.015)\end{array}$ & $\begin{array}{c}0.26^{* * *} \\
(0.015)\end{array}$ & $\begin{array}{c}0.42^{* * *} \\
(0.019)\end{array}$ \\
\hline Observations & 1,939 & 1,939 & 1,939 & 1,939 \\
\hline R-squared & 0.030 & 0.015 & 0.002 & 0.025 \\
\hline
\end{tabular}

This table displays the results of estimating the regression model laid out in equation (29) for each quartile of firm productivity, measured by number of products sold. 
Table A6: Event Study

\begin{tabular}{|c|c|c|c|c|c|c|}
\hline VARIABLES & $\begin{array}{c}(1) \\
\text { Product-level revenue }\end{array}$ & $\begin{array}{c}(2) \\
\text { Product-level revenue } \\
\end{array}$ & $\begin{array}{c}\text { (3) } \\
\text { Prods per firm-deset }\end{array}$ & $\begin{array}{c}(4) \\
\text { Prods per firm-dest }\end{array}$ & $\begin{array}{c}(5) \\
\text { Firms per prod-dest }\end{array}$ & $\begin{array}{c}(6) \\
\text { Firms per prod-dest }\end{array}$ \\
\hline$E U_{j} *$ Woven $_{k} * Y R 2008$ & $\begin{array}{c}0.04 \\
(0.055)\end{array}$ & $\begin{array}{l}-0.05 \\
(0.075)\end{array}$ & $\begin{array}{c}0.01 \\
(0.036)\end{array}$ & $\begin{array}{c}0.08^{*} \\
(0.045)\end{array}$ & $\begin{array}{c}0.02 \\
(0.052)\end{array}$ & $\begin{array}{l}-0.06 \\
(0.040)\end{array}$ \\
\hline$E U_{j} *$ Woven $_{k} * Y R 2009$ & $\begin{array}{c}0.01 \\
(0.044)\end{array}$ & $\begin{array}{c}-0.02 \\
(0.067)\end{array}$ & $\begin{array}{c}0.02 \\
(0.026)\end{array}$ & $\begin{array}{c}0.03 \\
(0.034)\end{array}$ & $\begin{array}{c}0.01 \\
(0.023)\end{array}$ & $\begin{array}{c}-0.00 \\
(0.022)\end{array}$ \\
\hline$E U_{j} *$ Woven $_{k} * Y R 2010$ & $\begin{array}{l}0.00 \\
(0.00)\end{array}$ & $\begin{array}{l}0.00 \\
(0.00)\end{array}$ & $\begin{array}{c}0.00 \\
(0.00)\end{array}$ & $\begin{array}{c}0.00 \\
(0.00)\end{array}$ & $\begin{array}{l}0.00 \\
(0.00)\end{array}$ & $\begin{array}{c}0.00 \\
(0.00)\end{array}$ \\
\hline$E U_{j} *$ Woven $_{k} * Y R 2011$ & $\begin{array}{l}0.12 * * * \\
(0.046)\end{array}$ & $\begin{array}{c}0.04 \\
(0.048)\end{array}$ & $\begin{array}{c}0.05^{*} \\
(0.033)\end{array}$ & $\begin{array}{c}0.05^{*} \\
(0.025)\end{array}$ & $\begin{array}{c}0.02 \\
(0.046)\end{array}$ & $\begin{array}{c}0.04 \\
(0.031)\end{array}$ \\
\hline$E U_{j} *$ Woven $_{k} * Y R 2012$ & $\begin{array}{c}0.19^{* * *} \\
(0.059)\end{array}$ & $\begin{array}{c}0.21^{* * *} \\
(0.074)\end{array}$ & $\begin{array}{r}0.11^{* * *} \\
(0.034)\end{array}$ & $\begin{array}{c}0.11^{* * *} \\
(0.035)\end{array}$ & $\begin{array}{l}0.08^{* *} \\
(0.037)\end{array}$ & $\begin{array}{l}0.07^{* *} \\
(0.031)\end{array}$ \\
\hline$E U_{j} *$ Woven $_{k} * Y R 2013$ & $\begin{array}{l}0.24^{* * *} \\
(0.085)\end{array}$ & $\begin{array}{c}0.24^{* * *} \\
(0.066)\end{array}$ & $\begin{array}{l}0.15^{* * *} \\
(0.045)\end{array}$ & $\begin{array}{l}0.24^{* * *} \\
(0.054)\end{array}$ & $\begin{array}{l}0.12^{* * *} \\
(0.031)\end{array}$ & $\begin{array}{l}0.06^{*} \\
(0.034)\end{array}$ \\
\hline Constant & $\begin{array}{c}16.06 * * * \\
(0.007)\end{array}$ & $\begin{array}{c}16.07 * * * \\
(0.008)\end{array}$ & $\begin{array}{r}2.22^{* * *} \\
(0.004)\end{array}$ & $\begin{array}{r}2.18^{* * *} \\
(0.004)\end{array}$ & $\begin{array}{r}6.59^{* * *} \\
(0.005)\end{array}$ & $\begin{array}{l}6.61^{* * *} \\
(0.004)\end{array}$ \\
\hline Observations & 83,326 & 83,159 & 34,068 & 36,781 & 2,566 & 2,544 \\
\hline R-squared & 0.606 & 0.617 & & & & \\
\hline Firm-prod FE & $\mathrm{x}$ & $\mathrm{x}$ & & & & \\
\hline Firm-dest FE & & & $\mathrm{x}$ & $\mathrm{x}$ & & \\
\hline Dest-prod FE & & & & & $\mathrm{x}$ & $\mathrm{x}$ \\
\hline Woven-Post FE & $\mathrm{x}$ & & $\mathrm{x}$ & & $\mathrm{x}$ & \\
\hline Dest-Year FE & $\mathrm{x}$ & $\mathrm{x}$ & $\mathrm{x}$ & $\mathrm{x}$ & $\mathrm{x}$ & $\mathrm{x}$ \\
\hline Dest-Woven FE & $\mathrm{x}$ & & $\mathrm{x}$ & $\mathrm{x}$ & $\mathrm{x}$ & \\
\hline $\begin{array}{l}\text { Dest-Prod FE } \\
\text { Woven-Year FE }\end{array}$ & & $\mathrm{x}$ & & $\mathrm{x}$ & & $\mathrm{x}$ \\
\hline $\begin{array}{l}\text { Prod-Year FE } \\
\text { error cluster }\end{array}$ & prod & $\begin{array}{c}\mathrm{x} \\
\text { prod }\end{array}$ & firm & firm & prod & $\begin{array}{c}\mathrm{x} \\
\text { prod }\end{array}$ \\
\hline
\end{tabular}

This table displays the results of estimating the event-study framework outlined in section 5.4. 